\title{
Time Trends in Healthcare-Detected Incidence of Anorexia Nervosa and Bulimia Nervosa in the Norwegian National Patient Register (2010-2016)
}

\begin{tabular}{|r|l|}
\hline Journal: & International Journal of Eating Disorders \\
\hline Manuscript ID & IJED-18-0110.R2 \\
\hline Wiley - Manuscript type: & Original Article \\
\hline Complete List of Authors: & $\begin{array}{l}\text { Reas, Deborah; Oslo University Hospital, Division of Mental Health and } \\
\text { Addiction, Regional Department for Eating Disorders; University of Oslo, } \\
\text { Department of Psychology, Faculty of Social Sciences } \\
\text { Rø, Øyvind; Oslo University Hospital, Division of Mental Health and } \\
\text { Addiction, Regional Department of Eating Disorders; University of Oslo, } \\
\text { Faculty of Medicine, Institute of Clinical Medicine }\end{array}$ \\
\hline Keywords: & $\begin{array}{l}\text { Incidence, Anorexia Nervosa, Bulimia Nervosa, Epidemiology, Time Trends, } \\
\text { Medical Register, Joinpoint }\end{array}$ \\
\hline &
\end{tabular}


Time Trends in Healthcare-Detected Incidence of Anorexia Nervosa and Bulimia Nervosa in the Norwegian National Patient Register (2010-2016)

Deborah Lynn Reas, $\mathrm{PhD}^{1,2}$ and Øyvind Rø, MD, $\mathrm{PhD}^{1,3}$

${ }^{1}$ Regional Department for Eating Disorders, Division of Mental Health and Addiction, Oslo University Hospital, Norway

${ }^{2}$ Department of Psychology, Faculty of Social Sciences, University of Oslo, Norway

${ }^{3}$ Institute of Clinical Medicine, Faculty of Medicine, University of Oslo, Norway

*Correspondence to: Deborah Lynn Reas, PhD, Regional Department of Eating Disorders, Division of Mental Health and Addiction, Oslo University Hospital, P.O. Box 4956 Nydalen, N-0424 Oslo, Norway; Tel: 23016 323; E-mail: deborah.lynn.reas@,ous-hf.no

Word count: 250 (abstract), 4498 (main text)

Running Head: TRENDS IN HEALTHCARE-DETECTED INCIDENCE 
Abstract

2 Objective: Few studies have investigated temporal trends in the incidence of eating disorders. This

3 study investigated time trends in the age- and sex-specific incidence of healthcare-detected

4 anorexia nervosa (AN) and bulimia nervosa (BN) from 2010 to 2016. Methods: Data were

5 retrieved from the Norwegian National Patient Register as defined by the International

6 Classification of Diseases (ICD-10): narrowly-defined AN (F50.0), broadly-defined AN (F50.0 +

7 50.1), narrowly-defined $\mathrm{BN}$ (F50.2), and broadly-defined $\mathrm{BN}(\mathrm{F} 50.2+50.3)$. The average annual

8 percent changes (AAPC) in incidence rates (IR) were examined by Joinpoint regression analyses.

9 Results: The overall (i.e., both genders, ages 10-49) rates of AN were stable across the 7-year

10 period, with IRs ranging from 18.8 to 20.4 per 100,000 for narrowly-defined AN and 33.2 to 39.5

11 per 100,000 for broadly-defined $\mathrm{AN}$, whereas overall rates of $\mathrm{BN}$ declined. Age- and gender-

12 stratification revealed a significant annual increase in AN (narrow and broad) among 10-14 year-

13 old girls. The incidence of broadly-defined AN increased significantly among females aged 15-19

14 years between 2010 and 2012, before levelling off. Significant declines in the incidence of

15 narrowly- and broadly-defined $\mathrm{BN}$ among females occurred. Incidence rates among males was

16 stable and comparatively low, with no significant trends toward increasing or decreasing rates of

17 AN or BN over time. Discussion: Although register-based studies provide an underestimate of the

18 true incidence and may not accurately reflect population-level changes in true ED occurrence, this

19 study extends our knowledge regarding trends in the detected incidence of eating disorders into the

20 second decade of the $21^{\text {st }}$ century.

22 Keywords: Incidence, Time-trends, Anorexia Nervosa, Bulimia Nervosa, Epidemiology, Joinpoint 
Time Trends in Healthcare-Detected Incidence of Anorexia Nervosa and Bulimia Nervosa in the Norwegian National Patient Register (2010-2016) and bulimia nervosa $(\mathrm{BN})$ has increased over the past decades is a subject of debate. Long-term epidemiological data are valuable yet challenging to obtain and interpret, and disposed to wellknown methodological challenges (for reviews, see Hart, Granillo, Jorm, \& Paxton, 2011; Hoek, 2006, 2016; Hoek \& van Hoeken, 2003; Hsu, 1996; Keski-Rahkonen \& Mustelin, 2016; Smink, van Hoeken, \& Hoek, 2012; Wade, Keski-Rahkonen, \& Hudson, 2011). Incidence estimates are less commonly reported than prevalence, the latter of which refers to the total number of cases in a defined population within a time period, rather than the rate of occurrence of new cases. Aside from a few pediatric surveillance systems for early-onset childhood cases of restricting eating disorders (EDs) (Pinhas, Morris, Crosby, \& Katzman, 2011), the ED field is lacking prospective, populationbased surveillance studies to detect and monitor trends in incidence over time. This situation was recently complicated further by the removal of items related to eating disorders from the Center for Disease Control (CDC) Youth Risk Behavioral Surveillance System in the US (AED, October, 2017). Although single timepoint estimates from high-risk or community samples exist (Hoek et al., 2005; Isomaa, Isomaa, Marttunen, Kaltiala-Heino, \& Bjorkqvist, 2009; Keski-Rahkonen et al., 2009; Keski-Rahkonen et al., 2007; Nagl et al., 2016; Stice, Marti, \& Rohde, 2013; van Hoeken, Veling, Smink, \& Hoek, 2010), along with registry-based studies tracking developments from the 1930s to late 1990s (see reviews by Hoek \& van Hoeken, 2003; Hsu, 1996), more recent knowledge of whether eating disorders are increasing or decreasing since the year 2000 has remained limited to few sources. 
Worldwide, information on recent time-trends in incidence has been largely derived from

2 psychiatric or primary care registers in four countries, namely Denmark, Sweden, the Netherlands, and the UK (Gammelmark et al., 2015; Holland, Hall, Yeates, \& Goldacre, 2016; Javaras et al., 2015; Micali, Hagberg, Petersen, \& Treasure, 2013; Smink et al., 2016; Steinhausen \& Jensen, 2015; van Son, van Hoeken, Bartelds, van Furth, \& Hoek, 2006). In Denmark, an investigation of the Danish Central Psychiatric Research Register (DCPR) found an overall increase in AN from 1995 to 2010 in females aged 4 to 65 years (9.9 to 19.3/100,000), with the most frequent incidence of AN among girls aged 12-15 years (29.2 to 61.4/100,000) (Steinhausen \& Jensen, 2015), whereas lower and stable incidence rates of $\mathrm{BN}$ were detected. However, results were partially attributable to increases in the utilization of mental healthcare services generally in Denmark, with stable trends for $\mathrm{BN}$ becoming negative after adjustment to indicate a significant decline.

In Sweden, a study which tracked incidence rates between 1987 and 2010 for those born between 1979 and 2001 found considerable increases in AN after the year 2000 (Javaras et al., 2015). The most frequent incidence for females was 206 per 100,000 cases at a peak age of 14-15 years versus 13 per 100,000 cases for males at a peak age of 12-13 years. Results were linked to period effects rather than birth cohort effects, meaning that the incidence of detected ED did not differ between those born in the 1980s versus 1990s (Javaras et al., 2015). Yet findings were likely greatly influenced by the expansion of Swedish healthcare register coverage for EDs in the 2000s (e.g., the inclusion of all outpatient clinics), rendering it difficult to infer conclusions about time trends in true incidence due to the noted period effects.

Within a network of general practitioners representing $1 \%$ of the total Dutch population, there was a relatively stable rate of AN for both genders over three decades, with the exception of a significant initial increase in AN among 15-19 year old females (56.4/100,000 to 113.1/100,000 to 
1 97.0/100,000), while rates of BN steadily declined between 1985 and 2010 (Smink et al., 2016; van

2 Son et al., 2006). 11 (Holland et al., 2016). Midthune, 2000).

Several studies have been based on the General Practice Research Database in the UK (Currin, Schmidt, Treasure, \& Jick, 2005; Micali et al., 2013; Turnbull, Ward, Treasure, Jick, \& Derby, 1996), which is a primary care register covering approximately $5 \%$ of the UK population. Collectively, these studies have found declining rates of BN following a peak in 1996, followed by stabilization in the 2000 s, whereas overall rates of AN remained relatively stable throughout the 90 s and 2000s (Currin et al., 2005; Micali et al., 2013; Turnbull et al., 1996). In contrast, a study of hospital admissions in England reported increasing rates of first-time AN admissions from 2.7 to 6.3/100,000 per females aged 10 to 44 years between the periods of 1968-1971 and 2007-2011

Collectively, the evidence appears to converge upon downward trends in the healthcaredetected incidence of $\mathrm{BN}$ over the past decades, whereas findings for $\mathrm{AN}$ are less consistent. The available data on incidence trends during the 2000s, especially since 2010 , remain scarce, with information drawn from relatively few sources. Additional data from a unique source may shed light on the reliability and durability of emergent trends, serving as a useful point of reference for existing and future studies. Moreover, recent advancements in regression analyses to model time trends have seldom been applied within the eating disorders field, despite being standard practice for examining trends in the mortality and incidence of other illnesses, such as cancer (Kim, Fay, Feuer, \&

To our knowledge, only one study has reported average annual percentage changes in ED (Steinhausen \& Jensen, 2015), which is an informative method to infer the magnitude, significance, and directionality of time trends. Due to low base rates of EDs in the community and the expense of 
1 consecutively surveying the population, registries remain a valuable resource to measure time trends

2 in healthcare-detected incidence despite known shortcomings (Hoek, 2016; Mond, 2015). To date,

3 no studies of incidence in EDs have been published from Norway. Yet, similar to other Northern

4 European countries, register-based estimates benefit from a relatively stable population and reliable

5 census data due to strict reporting requirements, universal healthcare coverage, and a national

6 patient register with nearly $100 \%$ coverage. The present study investigated the average annual

7 percent changes in the age- and sex-adjusted incidence of narrowly- and broadly-defined anorexia nervosa (AN) and bulimia nervosa (BN) over a 7-year period from 2010 to 2016.

Method

Mid-year population data were obtained from annual census data from Statistics Norway

11 (SSB, 2016) to calculate year-specific, age-specific, and sex-specific incidence rates per 100,000.

12 The numerator was the number of incident cases detected within the given age- and sex category

13 during the specified time interval, and the denominator was the number of illness-free persons at-

14 risk in the same category. To allow for symptom heterogeneity, and in line with the DSM-5 changes

15 (APA, 2013) as well as proposals by the ICD-11 Eating Disorders Consultation Group to broaden

16 diagnostic categories (Al-Adawi et al., 2013), we used both narrow and broad definitions of AN and

17 BN. Cases were defined according to the International Classification of Diseases and Related Health

18 Problems, 10th edition (WHO, 1992) as follows: narrowly-defined AN (50.0), broadly-defined AN

19 (50.0 +50.1 or "atypical AN"), narrowly-defined BN (50.2), and broadly-defined BN $(50.2+50.3$

20 or "atypical BN").

21 The incidence data were retrieved from the National Patient Register (NPR), which is a

22 national health register managed by the Norwegian Directorate of Health covering all sectors of the

23 specialized health care services. Personal identification numbers have been reported to the NPR 
1 from 2008 onwards, which has enabled researchers and policy makers to follow the disease

2 trajectory of patients between sectors and hospitals thereafter. For the calculations, we excluded all

3 individuals who had a diagnosis of 50.0, 50.1, 50.2, or 50.3 in 2008 and 2009 to create a lag period

4 and minimize the risk of including potentially prevalent (i.e., not incident) cases during the first 48

5 months after linkage was possible in the National Patient Register. Incident cases were identified by

6 a first-time registration of either a primary or auxillary diagnosis of ICD-10 F50.0-50.3 between

7 January 1, 2010 and December $31^{\text {st }}$, 2016. A maximum of one registration per diagnostic entity was

8 allowed, yet similar to the method by Zerwas et al. (2015), diagnoses were not mutually exclusive;

9 thus, individuals could contribute to the incidence rate of $\mathrm{AN}$ at one time point and contribute to the

10 incidence rate of $\mathrm{BN}$ at a different time point.

11 In Norway, financial compensation for services mandates the registration of diagnoses to the

12 NPR which ensures nearly $100 \%$ coverage. This includes mandatory reporting of diagnostic

13 information for all publicly-funded specialized health care including inpatient, day patient, and

14 outpatient visits in secondary healthcare, including private practitioners or institutions with a

15 government contract to perform consultations (Norwegian Directorate of Health, 2012). Specialists

16 (i.e., psychiatrists or psychologists) assume responsibility for the diagnostic evaluation. There is no

17 formal requirement for a specific standardized assessment in mental healthcare when evaluating a

18 patient, and diagnostic evaluation typically involves a clinical evaluation, also in combination with a

19 structured interview. Psychiatric diagnoses are registered in the patient's medical record and

20 transferred electronically to the NPR. Data were anonymized and de-identified by the data

21 controller prior to release and no written consent from patients was required, in accordance with

22 applicable laws and regulations. This study was approved by the Regional Ethics Committee and

23 Data Protection Officer at Oslo University Hospital. 
$\underline{\text { Statistical Analysis }}$

Total, sex-specific, and age-specific incidence rates were calculated per 100,000 persons and corresponding Poisson 95\% confidence intervals computed using MedCalc version 18.0. Age groupings for males and females were stratified into 5-year bands for the youngest groups, thereafter 10-year bands in line with prior studies (i.e., Micali et al., 2013): 10-14, 15-19, 20-29, 30-39, and 40-49 years. To identify time trends, Joinpoint regression models were used to fit observed time trend data to linear functions. The Joinpoint regression program is a trend analysis software developed by the US National Cancer Institute for the analysis of data from the Surveillance Epidemiology and End Results (SEER) Program (NIH, 2017). This method depicts observed and modeled datapoints by connecting several different line segments on a log scale at "joinpoints," which segments the interpolation line rather than estimating one linear trend (Kim et al., 2000). This approach has two major advantages, estimating the magnitude of apparent increases or decreases by calculating the annual percent change (APC) in incidence for each time interval or segment (along with corresponding 95\% Cis) and identifying years when changes in trend direction occur. The average annual percentage change (AAPC) in incidence is also calculated to provide a summary statistic of trends over the entire period. The AAPC is computed as a weighted average of the APCs, enabling direct comparisons between the different age groups. If there is no change in the trend direction (i.e., no joinpoints), the APC will therefore equal the AAPC. Tests of significance used a Monte Carlo permutation method (4499 permutations) and significance was set at an alpha level of .05 . $699(5.5 \%)$ of cases were males and 11,912 (94.5\%) were females. Table 1 summarizes the sample 
1 details. Overall (i.e., both genders, all ages 10-49), there was no significant change in the average

2 annual percentage change (AAPC) of narrow or broad AN across the 7-year period. The AAPC for

3 narrowly-defined AN was $0.33 \%$ [95\% CI: -2.7, 3.5], with IRs of 18.8 per 100,000 [95\% CI: 17.2 ,

420.6 ] in 2010 and 20.4 per 100,000 [95\% CI: 18.7, 22.1] in 2016. The AAPC for broadly-defined

5 AN was also non-significant at $2.99 \%$ per year [95\% CI: $-0.4,6.5]$ with IRs of 33.2 per 100,000 in

62010 [95\% CI: 31.0, 36.5] and 39.5 per 100,000 in 2016 [95\% CI: 37.2, 41.8]. A significant

7 decrease occurred in the overall incidence of BN (i.e., both genders, 10-49 yrs) across the 7-year

8 period. Narrowly-defined BN decreased significantly at $-4.20 \%$ per year [95\% CI: $-7.5,-0.7$, with

9 IRs declining from 18.5 per 100,000 in 2010 [95\% CI: 16.9, 20.2] to 16.1 per 100,000 in 2016 [95\%

10 CI: 14.6, 17.2]. Likewise, broadly-defined BN had a significant annual decline of -3.32\% [95\% CI: -

$116.3,-0.2]$, decreasing from 29.40 per 100,000 [95\% CI: 27.4, 31.5] in 2010 to 26.9 per 100,000

12 [95\% CI: $24.9,28.8]$ in 2016.

Figure 1 displays the average annual percentage change (AAPC) in incidence rates stratified

14 by gender per 100,000 person-years. In the total female group (aged 10-49 yrs), no significant time

15 trends toward increasing or decreasing rates of AN were detected. However, there was a significant

16 average annual decline of $4.19 \%$ for narrowly-defined $\mathrm{BN}$ and a significant annual decline of $3.47 \%$

17 for broadly-defined BN. As shown in Figure 1, overall rates for males were comparatively low and

18 stable over time, with no significant trends toward increasing or decreasing rates, nor were any

19 joinpoints detected. In males, the overall incidence of narrowly-defined AN was 2.22 per 100,000

20 in 2010 [ $95 \%$ CI: $1.49,3.16$ ] and 2.24 per 100,000 in 2016 [95\% CI: $1.52,3.15]$, while the

21 corresponding IR for narrowly-defined $\mathrm{BN}$ in males was 1.33 per 100,000 in $2010[0.78,2.10]$ and

220.91 per 100,000 in $2016[0.43,1.46]$. The female to male ratio was approximately $13: 1$ for 
1 narrowly-defined AN, 14:1 for broadly-defined AN, 24:1 for narrowly-defined BN, and 25.6:1 for

2 broadly-defined BN.

3

Table 2 presents the age-adjusted incidence rates in females (95\% CIs). The most frequent incidence of AN (both narrow and broad) was found among females aged 15-19 years old. The most frequent incidence of BN (both narrow and broad) was found among females aged 20-29 years. A divergent age-related pattern in time-trends of the incidence of AN was observed between younger and older age groups, characterized by increasing rates among the youngest groups and either stable or decreasing rates of AN in the older groups. Specifically, a significant average annual increase of $8.6 \%$ for narrowly-defined AN was found among the 10-14 year old girls, with IRs increasing from 29.9 per 100,000 in 2010 [95\% CI: $22.0,40.0$ ] to 58.2 per 100,000 in 2016 [95\% CI: 70.6, 108.4]. Broadly-defined AN also increased significantly among 10-14 year old girls by $12.1 \%$ per year, with IRs increasing from 39.1 per 100,000 in 2010 [95\% CI : 29.8, 50.4] to 85.9 per 100,000 in 2016 [95\% CI : 71.8, 102.1]. Among 15-19 year old females, a significant average annual increase of $6.4 \%$ per year was observed for broadly-defined AN, with IRs increasing from 185.8 per 100,000 in 2010 [95\% CI: $165.0,208.4$ ] to 265.02 per 100,000 in 2016 [95\% CI: 264.0, 291.7]. A single joinpoint was found among the 15-19 year olds, with an initial increase in broadlydefined AN until 2012, before levelling off (see Supplemental Figure S1). Age-stratification showed significantly declining rates of narrowly- and broadly-defined BN among the 20-29 year olds (see Supplemental Figure S2). The one exception to nearly-universal declining rates of BN was a positive, yet non-significant, trend in the incidence of broadly-defined BN among girls aged 10-14 years (i.e., from 1.96/100,000 in 2010 to 3.30/100,000 in 2016). For males, the age-adjusted incidence rates were stable and comparatively low over time, with no significant trends toward 
1 increasing or decreasing rates, nor were any joinpoints detected (data shown in the online

2 supplemental materials, Supplemental Table S1).

3

4

5

6

7

\section{Discussion}

The main objective of the present study was to investigate time trends in the healthcaredetected incidence of narrowly- and broadly-defined anorexia nervosa and bulimia nervosa using a national patient register. Several main conclusions can be drawn based upon the findings. First, although there was overall stability in the total incidence of $\mathrm{AN}$ in both genders, divergent age- and gender-related trends were detected. Specifically, there was a significant increase in the annual incidence of detected AN among 10-14 year-old girls (i.e., 29.99 to 58.27 per 100,000 for narrowlydefined AN; 39.13 to 85.96 per 100,000 for broadly-defined AN), as well as a significant increase in broadly-defined AN among 15-19 year olds (185.8 to 265.0 per 100,000). Incidence rates of AN among the youngest girls (aged 10-14 yrs) rose steadily across the 7-year period in Norway, whereas the incidence of broadly-defined AN in 15-19 year old females stabilized following 2012. Collectively, finding are consistent with several prior studies reporting increasing trends in AN specifically among younger females (Gammelmark et al., 2015; Lucas, Crowson, O'Fallon, \& Melton, 1999; van Son et al., 2006). Smink et al. (2016) reported an increase in incidence of AN among 15 to 19 year-old females in the 1980s and 1990s, with stabilization thereafter.

Second, we observed declines in the detected incidence of bulimia nervosa. This finding is largely consistent with studies from the 1990s and early 2000s (Currin et al., 2005; Smink et al., 2016; Steinhausen \& Jensen, 2015), and provides evidence of continued downward trends in the detected incidence of $\mathrm{BN}$ into the 2010s. Third, the annual incidence of eating disorders among men was stable, and compared to women, disproportionately low, with male:female ratios of approximately 1:14 for $\mathrm{AN}$ and 1:26 for $\mathrm{BN}$. In clinical populations, a 1:10 male: female ratio is 
1 often considered the expected gender ratio (APA, 2013), with even less pronounced gender

2 differences in eating disorder symptoms in the community (Striegel-Moore et al., 2009). This

3 suggests that despite growing awareness of the occurrence of eating disorders in boys and men

4 (Mangweth-Matzek \& Hoek, 2017; Murray et al., 2017; Reas \& Stedal, 2015), many challenges

5 remain related to the detection, diagnosis, assessment, and treatment of males with eating disorders

6 (Murray, Griffiths, \& Nagata, 2018).

$7 \quad$ Fourth, and in line with other register-based studies, these data provide an underestimate of

8 the "true" occurrence of ED in the community because only a fraction of individuals with a

9 diagnosable ED ever seek or receive treatment (Keski-Rahkonen \& Mustelin, 2016). Our estimates

10 of the incidence of ED are lower than community rates. For instance, the incidence of AN for our

11 15-19 year-old females, despite constituting the highest incident group, is approximately half of

12 that reported in a non-treatment-seeking sample of 15-19 year olds in Finland (i.e., 270 per 100,000

13 and 490 per 100,000 for narrow and broad AN, respectively) (Keski-Rahkonen et al., 2007).

14 Additionally, our rates of the incidence for healthcare-detected BN comprise roughly $25-30 \%$ of

15 that found in a Finnish community sample, for which detection occurred exclusively outside

16 healthcare settings (i.e., 210 per 100,000 for narrow $\mathrm{BN}$ and 280 per 100,000 for broad $\mathrm{BN}$ )

17 (Keski-Rahkonen et al., 2009). This reflects an unmet need for treatment, and is in line with a

18 systematic review which found that only $23.2 \%(95 \% \mathrm{CI}=16.6,31.4)$ of community cases with a

19 diagnosable eating disorder had received specialist treatment (Hart et al., 2011).

20 Whether AN is increasingly affecting younger girls, or whether increased rates reflect other

21 factors such as improved detection, public awareness, and service availability, remains unclear. One

22 study of outpatient referrals to a specialized ED service between 1985 and 2008 found that patients

23 referred in more recent years indeed had an earlier age of onset (Favaro, Caregaro, Tenconi, Bosello, 
1 \& Santonastaso, 2009). The rise in the incidence of AN in girls aged 10-14 years since 2010 is

2 worrisome and should be monitored carefully, as it carries important implications for treatment and

3 the timing of prevention. The majority of universal and selected prevention programs for eating

4 disorders target high school and university-aged women (Stice, Becker, \& Yokum, 2013; Stice,

5 Shaw, \& Marti, 2007). Although participants aged 15 or older often show greater improvements

6 following prevention trials than younger participants (Stice et al., 2007), this moderating effect for

7 age may attribute to a variety of methodological reasons (e.g., design issues, floor effects, choice of assessment) rather than a lack of need or true benefit. The present findings suggests it is important to

9 continue to tailor and improve prevention efforts for younger adolescents as well as older

10 adolescents, ideally coupled with strong parental engagement (Hart, Cornell, Damiano, \& Paxton, $112015)$.

Regarding the declining rates of $\mathrm{BN}$, it is possible that secondary register-based estimates

13 for $\mathrm{BN}$, such as ours, are especially prone to underestimation, as individuals with $\mathrm{BN}$ increasingly 14 seek treatment at lower levels of care such as self-help and online resources. However, a primary15 care based register study also found a decline in $\mathrm{BN}$ when examining time trends across three 16 decades (Smink et al., 2016). Some have speculated that an initial influx of longstanding cases and 17 greater detection of BN occurred in the 1980s-90s following the recognition of the disorder, and 18 settling thereafter (Fombonne, 1996). Yet as our observation period started in 2010, the residual 19 effect stemming from an initial artificial diagnostic inflation is minimal. As declines occurred in 20 parallel with increasing awareness of binge eating disorder (BED), it remains possible that cases of 21 BED are increasingly being recognized in Norway, resulting in a shift toward the ICD category of 22 F.50.8. Unfortunately, no epidemiological data on BED are available in Norway, and BED was not 23 covered in this study, so this remains speculation. We note that significant declines occurred 
1 whether BN was defined either narrowly or broadly, suggesting a similar trend for "typical" or

2 "atypical" cases.

There are several notable strengths and limitations of register-based studies of incidence that warrant a general discussion. Changes in the incidence of healthcare-register-detected ED may reflect myriad factors other than actual increases or decreases in "true" incidence over time. Similar to all register-based studies, data are highly sensitive to changes in diagnostic or registration practices by clinicians, service availability and the number of specialists, improved awareness or ED mental health literacy in families, schools, and the community-at-large, as well as general trends toward increasing treatment-seeking and greater mental healthcare utilization, especially among young people, as has been found previously in Denmark (Steinhausen \& Jensen, 2015). Norway has also witnessed an overall increase mental healthcare utilization overall among young persons, particularly adolescent females. A 2018 report by the Norwegian National Institute of Public Health found that the percentage of teenage girls diagnosed with any mental health diagnosis has increased from 5\% in 2011 to 7\% in 2016, of which anxiety, mood, and adjustment disorders, as well as eating disorders, comprised the major diagnostic categories, often diagnosed concurrently (Reneflot et al., 2018). Although it is unknown why such increases in teenage girls have occurred, the report concluded it was unlikely that referral and diagnostic practices are primarily responsible, as no corresponding increases in mental healthcare treatment utilization were observed in other groups (p. 76, Reneflot et al., 2018).

It is considered a strength of the study that no formal changes to diagnostic criteria occurred during the observation period. Nevertheless, systematic changes in coding or registration procedures at the site or practitioner-level may have occurred. It is a limitation that linkage in the NPR is only available from 2008 onwards, sharply limiting the period of study observation and 
1 unfortunately preventing linkage with the medical birth registry. As such, the register may include

2 non-first instances of healthcare-detected cases, and this precludes any conclusions regarding the

3 peak age of incidence or time of onset, which is unknown. Data from 2008 and 2009 was excluded

4 from the analyses to create a delay, or lag, to reduce the potential risk of including prevalent cases.

5 The aim of this study, which focused on time trends in healthcare detected incidence across a

6 defined period, and the non-linkage with the birth registry renders this study less than ideally suited

7 for analyses of peak age at incidence or onset, which has been extensively addressed elsewhere

8 (Favaro et al., 2009; Javaras et al., 2015; Steinhausen \& Jensen, 2015; Zerwas et al., 2015).

9 The registry contains specialist-determined diagnoses, yet the diagnostic validity of the

10 register for the purpose of epidemiological research for eating disorders has not been specifically

11 tested or cross-checked with direct clinical examinations or other registries. Concordance is high

12 for illnesses such as cancer and stroke (Bakken et al., 2012; Varmdal et al., 2016), with excellent

13 specificity due to few false positives, but has only moderate sensitivity as an indicator of

14 psychiatric illnesses, such as anxiety and major depression (Torvik et al., 2018). Healthcare is

15 universal for residents of Norway, minimizing potential ascertainment bias due to limited finances

16 or inaccessibility of mental health services. The register has $100 \%$ coverage for both specialty

17 outpatient, day and inpatient visits, including private practitioners contracted to perform publically-

18 funded consultations, but does not include primary care visits. In Norway, as elsewhere in

19 Scandinavia, general practitioners (GPs) working in primary care function as a gateway to

20 receiving specialist healthcare. However GPs typically defer to specialists for in-depth assessment,

21 applying an "unspecified" eating disorder as the referral diagnosis, which limits the utility and

22 complicates the interpretation of primary care-based data in Norway. We have therefore focused

23 upon specialist or secondary care. Other types of studies and healthcare systems are more suitably 
1 designed to track trends in the first-line detected incidence of EDs by general practitioners (e.g.,

2 Micali et al., 2013; van Son et al., 2006).

This study included both primary and auxiliary diagnoses due to uncertainty related to how

4 individual specialists may register and rank comorbidity. To accommodate symptom heterogeneity,

5 we included both narrow and broad definitions of $\mathrm{AN}$ and $\mathrm{BN}$, and diagnoses were not mutually

6 exclusive as diagnostic fluctuation is common, especially from AN to BN (Eddy et al., 2008;

7 Keski-Rahkonen et al., 2009). Lastly, age groups were stratified into 5-year bands for the most at-

8 risk groups, thereafter 10-year bands, spanning the ages 10 to 49 years. A more nuanced

9 breakdown of age categories, as well as a broader age range (i.e., $\leq 9$ and $\geq 50$ yrs) was foregone

10 due to risk of having fewer than 5 cases per cell (except zeros), in which case the register blocked

11 the release of exact counts owing to privacy concerns. These methodological features may have

12 contributed to comparably higher incidence estimates than historically reported (see review by

13 Hoek \& van Hoeken, 2003), although we again emphasize our estimates comprise only one-third to

14 one-half of those reported in the community (Keski-Rahkonen et al., 2009; Keski-Rahkonen et al., 15 2007).

16 In conclusion, this study investigated annual time trends in the specialist healthcare-

17 detected incidence of eating disorders, applying a seldom-used method in the ED field to a novel

18 data source to determine the direction and magnitude of recent trends. Incidence data are far less

19 commonly reported than prevalence data, despite having important implications for public health

20 and healthcare provision, and offer valuable insight into detection and diagnostic practices. The

21 significant increase in the detected incidence of AN in girls aged 10-14 years old, both narrowly

22 and broadly-defined, is worrisome and should be monitored closely owing to important

23 implications for treatment and prevention. In comparison to community estimates (Keski- 
1 Rahkonen et al., 2009; Keski-Rahkonen et al., 2007), our study suggests that only one-half of

2 individuals with diagnosable $\mathrm{AN}$, and less than one-third of those with diagnosable $\mathrm{BN}$, received

3 specialist mental healthcare in Norway in recent years. Study findings provide additional evidence

4 to support two emergent trends identified during the first decade of the $21^{\text {st }}$ century—namely,

5 increases in the incidence of $\mathrm{AN}$ among younger females and near-universal declines in $\mathrm{BN}$ - to

6 extend our knowledge of trends in the healthcare-detected incidence of eating disorders into the 72010 s.

8

9

10

11 


\section{References}

AED. (October, 2017). 65 Bipartisan Members of Congress Urge CDC To Include Eating Disorders within National Surveillance Systems. [Press release]. Retrieved from https://www.aedweb.org/advocate/press-releases

Al-Adawi, S., Bryant-Waugh, R., Claudino, A., Hay, P. J., Moneleone, P., Norring, C., . . Uher, R. (2013). Revision of ICD - status update on feeding and eating disorders. Advances in Eating Disorders, 1(1), 10-20. doi:

https://doi.org/10.1080/21662630.2013.742971

APA. (2013). Diagnostic and Statistical Manual of Mental Disorders, fifth edition. Washington, DC: American Psychiatric Association.

Bakken, I. J., Gystad, S. O., Christensen, O. O., Huse, U. E., Laronningen, S., Nygard, J., .. . Larsen, I. K. (2012). Comparison of data from the Norwegian Patient Register and the Cancer Registry of Norway. Tidsskr Nor Laegeforen, 132(11), 1336-1340. doi:10.4045/tidsskr.11.1099

Currin, L., Schmidt, U., Treasure, J., \& Jick, H. (2005). Time trends in eating disorder incidence. $B r$ J Psychiatry, 186, 132-135. doi:10.1192/bjp.186.2.132

Eddy, K. T., Dorer, D. J., Franko, D. L., Tahilani, K., Thompson-Brenner, H., \& Herzog, D. B. (2008). Diagnostic crossover in anorexia nervosa and bulimia nervosa: implications for DSM-V. Am J Psychiatry, 165(2), 245-250. doi:10.1176/appi.ajp.2007.07060951

Favaro, A., Caregaro, L., Tenconi, E., Bosello, R., \& Santonastaso, P. (2009). Time trends in age at onset of anorexia nervosa and bulimia nervosa. J Clin Psychiatry, 70(12), 1715-1721. doi:10.4088/JCP.09m05176blu 
1 Fombonne, E. (1996). Is bulimia nervosa increasing in frequency? Int J Eat Disord, 19(3), 287-296.

2 doi:10.1002/(SICI)1098-108X(199604)19:3<287::AID-EAT8>3.0.CO;2-I

Gammelmark, C., Jensen, S. O., Plessen, K. J., Skadhede, S., Larsen, J. T., \& Munk-Jorgensen, P. (2015). Incidence of eating disorders in Danish psychiatric secondary healthcare 1970-2008. Aust N Z J Psychiatry, 49(8), 724-730. doi:10.1177/0004867414567758

Hart, L. M., Cornell, C., Damiano, S. R., \& Paxton, S. J. (2015). Parents and prevention: a systematic review of interventions involving parents that aim to prevent body dissatisfaction or eating disorders. Int J Eat Disord, 48(2), 157-169. doi:10.1002/eat.22284

Hart, L. M., Granillo, M. T., Jorm, A. F., \& Paxton, S. J. (2011). Unmet need for treatment in the eating disorders: a systematic review of eating disorder specific treatment seeking among community cases. Clin Psychol Rev, 31(5), 727-735. doi:10.1016/j.cpr.2011.03.004

Hoek, H. W. (2006). Incidence, prevalence and mortality of anorexia nervosa and other eating disorders. Curr Opin Psychiatry, 19(4), 389-394. doi:10.1097/01.yco.0000228759.95237.78

Hoek, H. W. (2016). Review of the worldwide epidemiology of eating disorders. Curr Opin Psychiatry, 29(6), 336-339. doi:10.1097/YCO.0000000000000282

Hoek, H. W., van Harten, P. N., Hermans, K. M., Katzman, M. A., Matroos, G. E., \& Susser, E. S. (2005). The incidence of anorexia nervosa on Curacao. Am J Psychiatry, 162(4), 748-752. doi:10.1176/appi.ajp.162.4.748

Hoek, H. W., \& van Hoeken, D. (2003). Review of the prevalence and incidence of eating disorders. Int J Eat Disord, 34(4), 383-396. doi:10.1002/eat.10222

Holland, J., Hall, N., Yeates, D. G., \& Goldacre, M. (2016). Trends in hospital admission rates for anorexia nervosa in Oxford (1968-2011) and England (1990-2011): database studies. J R Soc Med, 109(2), 59-66. doi:10.1177/0141076815617651 
1 Hsu, L. K. (1996). Epidemiology of the eating disorders. Psychiatr Clin North Am, 19(4), 681-700.

2 Isomaa, R., Isomaa, A. L., Marttunen, M., Kaltiala-Heino, R., \& Bjorkqvist, K. (2009). The prevalence, incidence and development of eating disorders in Finnish adolescents: a two-step 3-year follow-up study. Eur Eat Disord Rev, 17(3), 199-207. doi:10.1002/erv.919

Javaras, K. N., Runfola, C. D., Thornton, L. M., Agerbo, E., Birgegard, A., Norring, C., . . Bulik, C. M. (2015). Sex- and age-specific incidence of healthcare-register-recorded eating disorders in the complete swedish 1979-2001 birth cohort. Int J Eat Disord, 48(8), 10701081. doi:10.1002/eat.22467

Keski-Rahkonen, A., Hoek, H. W., Linna, M. S., Raevuori, A., Sihvola, E., Bulik, C. M., . . . Kaprio, J. (2009). Incidence and outcomes of bulimia nervosa: a nationwide populationbased study. Psychol Med, 39(5), 823-831. doi:10.1017/S0033291708003942

Keski-Rahkonen, A., Hoek, H. W., Susser, E. S., Linna, M. S., Sihvola, E., Raevuori, A., . . . Rissanen, A. (2007). Epidemiology and course of anorexia nervosa in the community. Am J Psychiatry, 164(8), 1259-1265. doi:10.1176/appi.ajp.2007.06081388

Keski-Rahkonen, A., \& Mustelin, L. (2016). Epidemiology of eating disorders in Europe: prevalence, incidence, comorbidity, course, consequences, and risk factors. Curr Opin Psychiatry, 29(6), 340-345. doi:10.1097/YCO.0000000000000278

Kim, H. J., Fay, M. P., Feuer, E. J., \& Midthune, D. N. (2000). Permutation tests for joinpoint regression with applications to cancer rates. Stat Med, 19(3), 335-351.

Lucas, A. R., Crowson, C. S., O'Fallon, W. M., \& Melton, L. J., 3rd. (1999). The ups and downs of anorexia nervosa. Int J Eat Disord, 26(4), 397-405. 
1 Mangweth-Matzek, B., \& Hoek, H. W. (2017). Epidemiology and treatment of eating disorders in men and women of middle and older age. Curr Opin Psychiatry, 30(6), 446-451. doi:10.1097/YCO.0000000000000356

Micali, N., Hagberg, K. W., Petersen, I., \& Treasure, J. L. (2013). The incidence of eating disorders in the UK in 2000-2009: findings from the General Practice Research Database. BMJ Open, 3(5). doi:10.1136/bmjopen-2013-002646

Mond, J. (2015). Have case-register studies of eating disorders incidence reached their use-by date? Aust N Z J Psychiatry, 49(8), 679-680. doi:10.1177/0004867415586603

Murray, S. B., Griffiths, S., \& Nagata, J. M. (2018). Community-Based Eating Disorder Research in Males: A Call to Action. J Adolesc Health, 62(6), 649-650. doi:10.1016/j.jadohealth.2018.03.008

Murray, S. B., Nagata, J. M., Griffiths, S., Calzo, J. P., Brown, T. A., Mitchison, D., . . Mond, J. M. (2017). The enigma of male eating disorders: A critical review and synthesis. Clin Psychol Rev, 57, 1-11. doi:10.1016/j.cpr.2017.08.001

Nagl, M., Jacobi, C., Paul, M., Beesdo-Baum, K., Hofler, M., Lieb, R., \& Wittchen, H. U. (2016). Prevalence, incidence, and natural course of anorexia and bulimia nervosa among adolescents and young adults. Eur Child Adolesc Psychiatry, 25(8), 903-918. doi:10.1007/s00787-015-0808-z

NIH. (2017). Joinpoint Regression Program, Version 4.5.0.1. Statistical Methodology and Applications Branch, Surveillance Research Program, National Cancer Institute. U.S. Department of Health and Human Services, National Institutes of Health, Bethesda, Maryland. https://seer.cancer.gov/seerstat/. 
1 Norwegian Directorate of Health. (2012). Norway and Health. An introduction. Department for Global Health. Oslo, Norway.

Pinhas, L., Morris, A., Crosby, R. D., \& Katzman, D. K. (2011). Incidence and age-specific presentation of restrictive eating disorders in children: a Canadian Paediatric Surveillance Program study. Arch Pediatr Adolesc Med, 165(10), 895-899. doi:10.1001/archpediatrics.2011.145

Reas, D. L., \& Stedal, K. (2015). Eating disorders in men aged midlife and beyond. Maturitas, 81(2), 248-255. doi:10.1016/j.maturitas.2015.03.004

Reneflot, A., Aarø, L. E., Aase, H., Reichborn-Kjennerud, T., Tambs, K., \& Øverland, S. (2018). Psykisk helse i Norge [Mental Health in Norway]. Oslo, Norway: Helse- og omsorgsdepartementet [Department of Health and Welfare]. Retrieved from www.fhi.no.

Smink, F. R., van Hoeken, D., Donker, G. A., Susser, E. S., Oldehinkel, A. J., \& Hoek, H. W. (2016). Three decades of eating disorders in Dutch primary care: decreasing incidence of bulimia nervosa but not of anorexia nervosa. Psychol Med, 46(6), 1189-1196. doi:10.1017/S003329171500272X

Smink, F. R., van Hoeken, D., \& Hoek, H. W. (2012). Epidemiology of eating disorders: incidence, prevalence and mortality rates. Curr Psychiatry Rep, 14(4), 406-414. doi:10.1007/s11920012-0282-y

SSB. (2016). Statistics Norway [Statistisk Sentralbyrå]. Statbank. Retrieved from: www.ssb.no [Press release]. Retrieved from www.ssb.no

Steinhausen, H. C., \& Jensen, C. M. (2015). Time trends in lifetime incidence rates of first-time diagnosed anorexia nervosa and bulimia nervosa across 16 years in a Danish nationwide psychiatric registry study. Int J Eat Disord, 48(7), 845-850. doi:10.1002/eat.22402 
Stice, E., Becker, C. B., \& Yokum, S. (2013). Eating disorder prevention: current evidence-base and future directions. Int J Eat Disord, 46(5), 478-485. doi:10.1002/eat.22105

Stice, E., Marti, C. N., \& Rohde, P. (2013). Prevalence, incidence, impairment, and course of the proposed DSM-5 eating disorder diagnoses in an 8-year prospective community study of young women. J Abnorm Psychol, 122(2), 445-457. doi:10.1037/a0030679

Stice, E., Shaw, H., \& Marti, C. N. (2007). A meta-analytic review of eating disorder prevention programs: encouraging findings. Annu Rev Clin Psychol, 3, 207-231. doi:10.1146/annurev.clinpsy.3.022806.091447

Striegel-Moore, R. H., Rosselli, F., Perrin, N., DeBar, L., Wilson, G. T., May, A., \& Kraemer, H. C. (2009). Gender difference in the prevalence of eating disorder symptoms. Int J Eat Disord, 42(5), 471-474. doi:10.1002/eat.20625

Torvik, F. A., Ystrom, E., Gustavson, K., Rosenstrom, T. H., Bramness, J. G., Gillespie, N., . . Reichborn-Kjennerud, T. (2018). Diagnostic and genetic overlap of three common mental disorders in structured interviews and health registries. Acta Psychiatr Scand, 137(1), 54-64. doi:10.1111/acps.12829

Turnbull, S., Ward, A., Treasure, J., Jick, H., \& Derby, L. (1996). The demand for eating disorder care. An epidemiological study using the general practice research database. Br J Psychiatry, 169(6), 705-712.

van Hoeken, D., Veling, W., Smink, F. R., \& Hoek, H. W. (2010). The incidence of anorexia nervosa in Netherlands Antilles immigrants in the Netherlands. Eur Eat Disord Rev, 18(5), 399-403. doi:10.1002/erv.1040 
van Son, G. E., van Hoeken, D., Bartelds, A. I., van Furth, E. F., \& Hoek, H. W. (2006). Time trends in the incidence of eating disorders: a primary care study in the Netherlands. Int J Eat Disord, 39(7), 565-569. doi:10.1002/eat.20316

Varmdal, T., Bakken, I. J., Janszky, I., Wethal, T., Ellekjaer, H., Rohweder, G., . . Bonaa, K. H. (2016). Comparison of the validity of stroke diagnoses in a medical quality register and an administrative health register. Scand J Public Health, 44(2), 143-149. doi:10.1177/1403494815621641

Wade, T. D., Keski-Rahkonen, A., \& Hudson, J. I. (2011). Epidemiology of eating disorders. In T. Tsuang, M. Tohen, \& P. Jones (Eds.), Textbook of Psychiatric Epidemiology. (pp. 343-360). New York, NY: John Wiley \& Sons, Ltd.

WHO. (1992). International Classification of Diseases and Related Health Problems, 10th edition Geneva: World Health Organization.

Zerwas, S., Larsen, J. T., Petersen, L., Thornton, L. M., Mortensen, P. B., \& Bulik, C. M. (2015). The incidence of eating disorders in a Danish register study: Associations with suicide risk and mortality. J Psychiatr Res, 65, 16-22. doi:10.1016/j.jpsychires.2015.03.003

6

7

8

9

0

1

2

3

4

5


1 Table 1. Total sample characteristics during the study period (2010-2016)

2

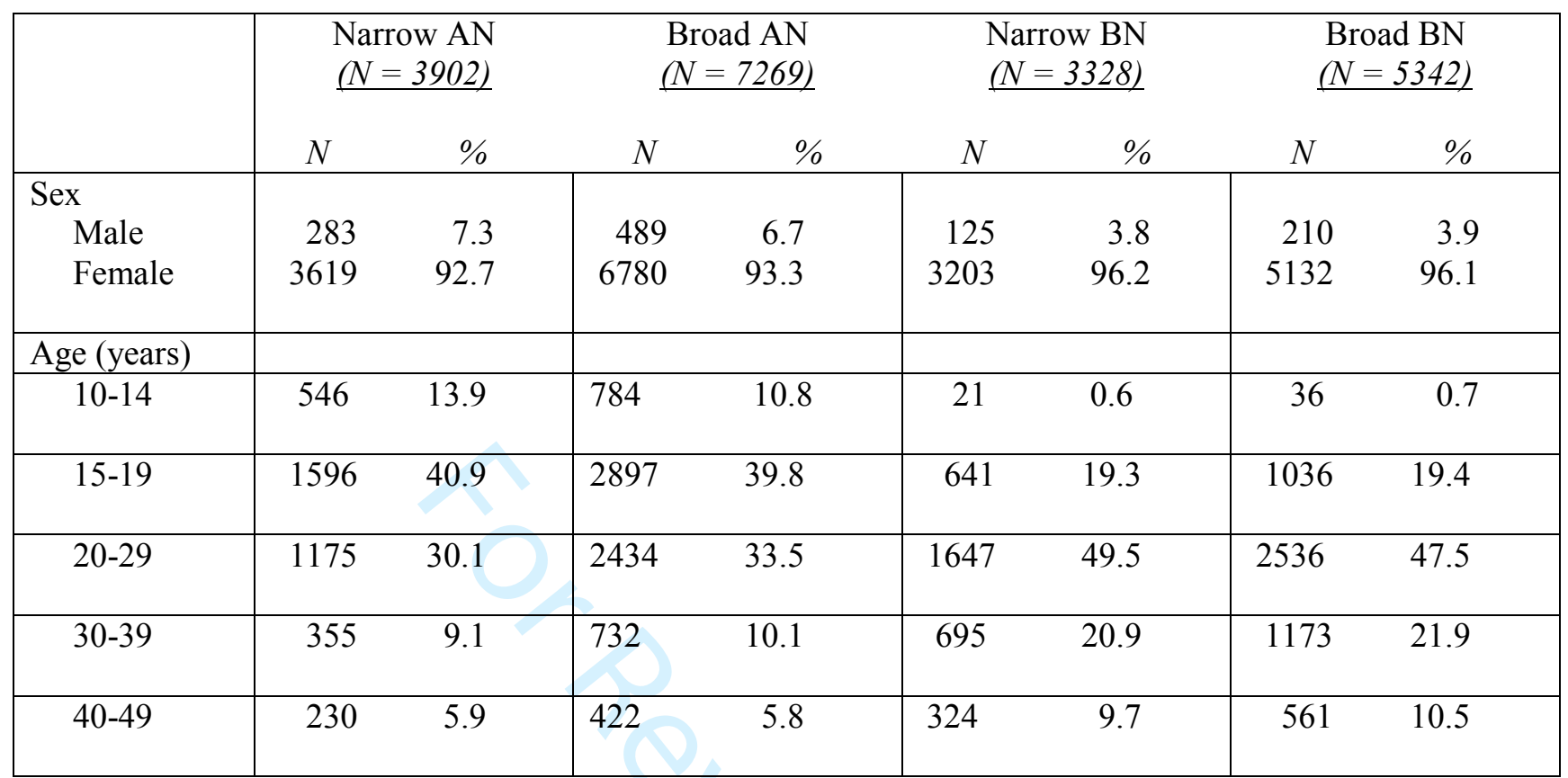

3 Note: Narrowly-defined AN = F50.0; broadly-defined AN = F50.0 + 50.1; narrowly-defined BN = F 50.2; 4 broadly-defined BN $=$ F50.2 +50.3 . 
TRENDS IN INCIDENCE

Table 2. Age-specific incidence rates $[95 \% \mathrm{CI}]$ per 100,000 and average annual percent change (AAPC), females

\begin{tabular}{|c|c|c|c|c|c|c|c|c|c|}
\hline Type of ED, age (yrs) & 2010 & 2011 & 2012 & 2013 & 2014 & 2015 & 2016 & \multicolumn{2}{|c|}{$\begin{array}{l}\text { APC/AAPC \% } \\
{[95 \% \text { CI }]}\end{array}$} \\
\hline \multicolumn{10}{|l|}{ Narrowly-defined AN } \\
\hline $10-14$ & $\begin{array}{c}29.99 \\
{[22.0,40.0)}\end{array}$ & $\begin{array}{c}42.57 \\
{[32.9,54.3]}\end{array}$ & $\begin{array}{c}41.63 \\
{[48.4,80.6]}\end{array}$ & $\begin{array}{c}41.82 \\
{[48.1,80.6]}\end{array}$ & $\begin{array}{c}42.51 \\
{[49.3,81.7]}\end{array}$ & $\begin{array}{c}51.18 \\
{[60.8,96.2]}\end{array}$ & $\begin{array}{c}58.17 \\
{[70.6,108.4]}\end{array}$ & \multicolumn{2}{|c|}{$\begin{array}{c}\mathbf{8 . 6}^{*} \\
{[3.6,13.9]}\end{array}$} \\
\hline $15-19$ & $\begin{array}{c}111.38 \\
{[95.4,129.2]}\end{array}$ & $\begin{array}{c}116.82 \\
{[100.5,134.7]}\end{array}$ & $\begin{array}{c}145.52 \\
{[127.3,165.6]}\end{array}$ & $\begin{array}{c}149.36 \\
{[131.1,169.9]}\end{array}$ & $\begin{array}{c}150.74 \\
{[132.2,171.2]}\end{array}$ & $\begin{array}{c}130.24 \\
{[113.1,149.3]}\end{array}$ & $\begin{array}{c}147.27 \\
{[128.9,167.5]}\end{array}$ & \multicolumn{2}{|c|}{$\begin{array}{c}3.7 \\
{[-1.5,9.2]}\end{array}$} \\
\hline $20-29$ & $\begin{array}{c}57.19 \\
{[49.03,66.32]}\end{array}$ & $\begin{array}{c}52.63 \\
{[44.9,61.3]}\end{array}$ & $\begin{array}{c}56.50 \\
{[48.6,65.3]}\end{array}$ & $\begin{array}{c}46.46 \\
{[39.4,54.4]}\end{array}$ & $\begin{array}{c}41.14 \\
{[34.6,48.6]}\end{array}$ & $\begin{array}{c}45.86 \\
{[38.9,53.6]}\end{array}$ & $\begin{array}{c}40.55 \\
{[34.1,47.8]}\end{array}$ & \multicolumn{2}{|c|}{$\begin{array}{c}-5.6 \\
{[-8.9,-2.2]}\end{array}$} \\
\hline $30-39$ & $\begin{array}{c}13.59 \\
{[9.9,18.2]}\end{array}$ & $\begin{array}{c}12.72 \\
{[9.2,17.2]}\end{array}$ & $\begin{array}{c}15.76 \\
{[11.8,20.7]}\end{array}$ & $\begin{array}{c}18.13 \\
{[13.8,23.3]}\end{array}$ & $\begin{array}{c}11.73 \\
{[8.34,16.0]}\end{array}$ & $\begin{array}{c}11.67 \\
{[8.3,15.9]}\end{array}$ & $\begin{array}{c}16.60 \\
{[12.5,21.6]}\end{array}$ & \multicolumn{2}{|c|}{$\begin{array}{c}1.0 \\
{[-8.0,10.9]}\end{array}$} \\
\hline $40-49$ & $\begin{array}{c}8.16 \\
{[5.42,11.8]}\end{array}$ & $\begin{array}{c}11.75 \\
{[8.43,15.9]}\end{array}$ & $\begin{array}{c}8.46 \\
{[5.71,12.08]}\end{array}$ & $\begin{array}{c}10.60 \\
{[7.5,14.5]}\end{array}$ & $\begin{array}{c}6.93 \\
{[4.83,10.2]}\end{array}$ & $\begin{array}{c}7.46 \\
{[4.91,10.85]}\end{array}$ & $\begin{array}{c}5.26 \\
{[3.17,8.21]}\end{array}$ & \multicolumn{2}{|c|}{$\begin{array}{c}-8.1 \\
{[-17.8,2.7]}\end{array}$} \\
\hline Total & $\begin{array}{c}\mathbf{3 6 . 2 8} \\
{[33.1,39.7]}\end{array}$ & $\begin{array}{c}\mathbf{3 8 . 1 2} \\
{[34.8,41.6]}\end{array}$ & $\begin{array}{c}\mathbf{4 2 . 2 9} \\
{[38.9,45.9]}\end{array}$ & $\begin{array}{c}\mathbf{4 1 . 4 5} \\
{[38.1,45.1]}\end{array}$ & $\begin{array}{c}\mathbf{3 7 . 7 0} \\
{[34.5,41.1]}\end{array}$ & $\begin{array}{c}\mathbf{3 7 . 5 6} \\
{[34.4,40.9]}\end{array}$ & $\begin{array}{c}\mathbf{3 9 . 5 5} \\
{[36.3,43.1]}\end{array}$ & \multicolumn{2}{|c|}{$\begin{array}{c}\mathbf{0 . 3 3} \\
{[-2.6,3.4]}\end{array}$} \\
\hline Broadly- defined AN & & & & & & & & \multirow{2}{*}{\multicolumn{2}{|c|}{$\begin{array}{c}\text { 12.1* }^{*} \\
{[8.1-16.4]}\end{array}$}} \\
\hline $10-14$ & $\begin{array}{c}39.13 \\
{[29.8,50.4]}\end{array}$ & $\begin{array}{c}53.71 \\
{[42.7,66.7]}\end{array}$ & $\begin{array}{c}58.83 \\
{[47.24,72.4]}\end{array}$ & $\begin{array}{c}57.09 \\
{[45.7,70.5]}\end{array}$ & $\begin{array}{c}66.43 \\
{[54,1,80.8]}\end{array}$ & $\begin{array}{c}80.45 \\
{[66.7,96.1]}\end{array}$ & $\begin{array}{c}85.96 \\
{[71.8,102.1]}\end{array}$ & & \\
\hline $15-19$ & $\begin{array}{c}185.78 \\
{[165.0,208.4]}\end{array}$ & $\begin{array}{c}210.22 \\
{[188.1,234.2]}\end{array}$ & $\begin{array}{c}265.94 \\
{[241.1,292.7]}\end{array}$ & $\begin{array}{c}283.07 \\
{[257.4,310.6]}\end{array}$ & $\begin{array}{c}274.58 \\
{[249.3,301.7]}\end{array}$ & $\begin{array}{c}250.67 \\
{[226.6,276.6]}\end{array}$ & $\begin{array}{c}265.02 \\
{[264.0,291.7]}\end{array}$ & $\begin{array}{c}2010-2012 \\
\mathrm{APC}=22.7 \\
{[10.1,67.6]} \\
2012-2016 \\
\mathrm{APC}=-0.9 \\
{[-8.8,7.7]}\end{array}$ & $\begin{array}{r}2010-2016 \\
\text { AAPC }=\mathbf{6 . 4} \\
{[0.9-12.3]}\end{array}$ \\
\hline $20-29$ & $\begin{array}{c}103.65 \\
{[92.6,115.7]}\end{array}$ & $\begin{array}{c}100.24 \\
{[89.5,111.9]}\end{array}$ & $\begin{array}{c}116.15 \\
{[104.7,128.5]}\end{array}$ & $\begin{array}{c}95.68 \\
{[85.4,106.8]}\end{array}$ & $\begin{array}{c}92.10 \\
{[82.2,102.9]}\end{array}$ & $\begin{array}{c}99.95 \\
{[89.6,111.1]}\end{array}$ & $\begin{array}{c}95.34 \\
{[85.3,106.2]}\end{array}$ & \multicolumn{2}{|c|}{$\begin{array}{c}-1.8 \\
{[-5.3,-1.9]}\end{array}$} \\
\hline $30-39$ & $\begin{array}{c}29.30 \\
{[23.8,35.7]}\end{array}$ & $\begin{array}{c}25.74 \\
{[20.6,31.8]}\end{array}$ & $\begin{array}{c}29.69 \\
{[24.1,36.2]}\end{array}$ & $\begin{array}{c}35.02 \\
{[28.9,42.0]}\end{array}$ & $\begin{array}{c}27.38 \\
{[22.1,33.6]}\end{array}$ & $\begin{array}{c}28.71 \\
{[23.3,35.1]}\end{array}$ & $\begin{array}{c}32.01 \\
{[26.3,38.7]}\end{array}$ & \multicolumn{2}{|c|}{$\begin{array}{c}1.4 \\
{[-3.8,6.9]}\end{array}$} \\
\hline $40-49$ & $\begin{array}{c}15.44 \\
{[11.56,20.2]}\end{array}$ & $\begin{array}{c}17.77 \\
{[13.6,22.8]}\end{array}$ & $\begin{array}{c}16.93 \\
{[12.9,21.8]}\end{array}$ & $\begin{array}{c}19.53 \\
{[15.2,24.7]}\end{array}$ & $\begin{array}{c}13.30 \\
{[9.81,17.6]}\end{array}$ & $\begin{array}{c}12.98 \\
{[9.54,17.3]}\end{array}$ & $\begin{array}{c}12.18 \\
{[8.85,16.4]}\end{array}$ & \multicolumn{2}{|c|}{$\begin{array}{c}-5.3 \\
{[-12.3,-2.2]}\end{array}$} \\
\hline Total & $\begin{array}{c}\mathbf{6 3 . 3 5} \\
{[59.1,67.9]}\end{array}$ & $\begin{array}{c}\mathbf{6 7 . 0 5} \\
{[62.7,71.7]}\end{array}$ & $\begin{array}{c}\mathbf{7 9 . 0 7} \\
{[74.3,84.0]}\end{array}$ & $\begin{array}{c}\mathbf{7 7 . 8 9} \\
{[73.2,82.8]}\end{array}$ & $\begin{array}{c}\mathbf{7 3 . 4 1} \\
{[68.9,78.1]}\end{array}$ & $\begin{array}{c}\mathbf{8 3 . 3 2} \\
{[78.6,88.4]}\end{array}$ & $\begin{array}{c}\mathbf{7 6 . 0 2} \\
{[71.4,80.8]}\end{array}$ & \multicolumn{2}{|c|}{$\begin{array}{c}\mathbf{3 . 1 4} \\
{[-0.5,7.0]}\end{array}$} \\
\hline
\end{tabular}

Note: Narrowly-defined AN $=$ F50.0; broadly-defined AN $=$ F50.0 + 50.1; narrowly-defined BN $=$ F50.2; broadly-defined BN $=$ F50.2 $+50.3 ;$ APC $=$ annual percent

change; AAPC $=$ average annual percentage change, which is a summary statistic over the entire period. ${ }^{*} \mathrm{p} \leq .05$. 
Table 1. Age-specific incidence rates [95\% CI] per 100,000 and average annual percent change (AAPC), females

\begin{tabular}{|c|c|c|c|c|c|c|c|c|}
\hline Type of ED, age [yrs] & 2010 & 2011 & 2012 & 2013 & 2014 & 2015 & 2016 & $\begin{array}{c}\text { APC/AAPC \% } \\
{[95 \% \mathrm{CI}]}\end{array}$ \\
\hline \multicolumn{9}{|l|}{ Narrowly-defined BN } \\
\hline $10-14$ & $\begin{array}{c}1.96 \\
{[0.40,5.73]}\end{array}$ & $\begin{array}{c}1.96 \\
{[0.41,5.74]}\end{array}$ & $\begin{array}{c}1.98 \\
{[0.41,5.79]}\end{array}$ & $\begin{array}{c}1.99 \\
{[0.41,5.82]}\end{array}$ & $\begin{array}{c}1.99 \\
{[0.41,5.82]}\end{array}$ & $\begin{array}{c}1.99 \\
{[0.41,5.83]}\end{array}$ & $\begin{array}{c}1.98 \\
{[4.09,5.79]}\end{array}$ & $\begin{array}{c}0.3 \\
{[0.0,0.5]}\end{array}$ \\
\hline $15-19$ & $\begin{array}{c}48.62 \\
{[38.3,60.9]}\end{array}$ & $\begin{array}{c}66.36 \\
{[54.2,80.4]}\end{array}$ & $\begin{array}{c}64.76 \\
{[52.8,78.6]}\end{array}$ & $\begin{array}{c}65.23 \\
{[53.2,79.1}\end{array}$ & $\begin{array}{c}53.78 \\
{[42.9,66.5]}\end{array}$ & $\begin{array}{c}44.22 \\
{[34.5,55.9]}\end{array}$ & $\begin{array}{c}50.74 \\
{[40.2,63.1]}\end{array}$ & $\begin{array}{c}-3.3 \\
{[-10.8,4.8]}\end{array}$ \\
\hline $20-29$ & $\begin{array}{c}81.07 \\
{[71.3,91.8]}\end{array}$ & $\begin{array}{c}79.92 \\
{[70.4,90.4]}\end{array}$ & $\begin{array}{c}79.36 \\
{[69.9,89.7]}\end{array}$ & $\begin{array}{c}64.27 \\
{[55.9,73.5]}\end{array}$ & $\begin{array}{c}58.02 \\
{[50.2,66.7]}\end{array}$ & $\begin{array}{c}62.23 \\
{[54.2,71.2]}\end{array}$ & $\begin{array}{c}63.45 \\
{[55.3,72.4]}\end{array}$ & $\begin{array}{c}-\mathbf{5 . 4 *} \\
{[-9.0,-1.7]}\end{array}$ \\
\hline $30-39$ & $\begin{array}{c}29.90 \\
{[24.3,36.4]}\end{array}$ & $\begin{array}{c}31.70 \\
{[26.1,38.5]}\end{array}$ & $\begin{array}{c}29.70 \\
{[24.1,36.2]}\end{array}$ & $\begin{array}{c}31.43 \\
{[25.7,38.1]}\end{array}$ & $\begin{array}{c}22.57 \\
{[17.8,28.3]}\end{array}$ & $\begin{array}{c}26.93 \\
{[21.7,33.1]}\end{array}$ & $\begin{array}{c}27.56 \\
{[22.3,33.8]}\end{array}$ & $\begin{array}{c}-2.9 \\
{[-7.5,2.0]}\end{array}$ \\
\hline $40-49$ & $\begin{array}{c}12.82 \\
{[9.31,17.2]}\end{array}$ & $\begin{array}{c}16.91 \\
{[12.9,21.8]}\end{array}$ & $\begin{array}{c}11.85 \\
{[8.54,16.0]}\end{array}$ & $\begin{array}{c}13.39 \\
{[9.90,17.8]}\end{array}$ & $\begin{array}{c}9.70 \\
{[6.70,13.5]}\end{array}$ & $\begin{array}{c}9.12 \\
{[6.28,12.8]}\end{array}$ & $\begin{array}{c}10.79 \\
{[7.68,14.8]}\end{array}$ & $\begin{array}{c}-7.0 \\
{[-14.3,0.9]}\end{array}$ \\
\hline Total & $\begin{array}{c}\mathbf{3 6 . 4 4} \\
{[33.2,39.8]}\end{array}$ & $\begin{array}{c}\mathbf{4 0 . 0 4} \\
{[36.7,43.6]}\end{array}$ & $\begin{array}{c}\mathbf{3 8 . 0 4} \\
{[34.8,41.5]}\end{array}$ & $\begin{array}{c}\mathbf{3 5 . 3 5} \\
{[32.2,38.7]}\end{array}$ & $\begin{array}{c}\mathbf{2 9 . 3 3} \\
{[26.5,32.4]}\end{array}$ & $\begin{array}{c}\mathbf{3 0 . 2 8} \\
{[27.4,33.4]}\end{array}$ & $\begin{array}{c}\mathbf{3 2 . 0 8} \\
{[29.1,35.3]}\end{array}$ & $\begin{array}{c}-\mathbf{4 . 1 9} * \\
{[-7.8,-0.4]}\end{array}$ \\
\hline \multicolumn{9}{|l|}{ Broadly-defined BN } \\
\hline $10-14$ & $\begin{array}{c}1.96 \\
{[0.43,5.72]}\end{array}$ & $\begin{array}{c}3.27 \\
{[1.06,7.64]}\end{array}$ & $\begin{array}{c}1.98 \\
{[0.41,5.79]}\end{array}$ & $\begin{array}{c}3.32 \\
{[1.1,7.74]}\end{array}$ & $\begin{array}{c}5.31 \\
{[2.29,10.46]}\end{array}$ & $\begin{array}{c}3.32 \\
{[1.08,7.75]}\end{array}$ & $\begin{array}{c}3.30 \\
{[1.07,7.71]}\end{array}$ & $\begin{array}{c}8.7 \\
{[-8.2,28.7]}\end{array}$ \\
\hline $15-19$ & $\begin{array}{c}74.23 \\
{[61.3,89.0]}\end{array}$ & $\begin{array}{c}104.68 \\
{[89.3,122.0]}\end{array}$ & $\begin{array}{c}100.36 \\
{[85.3,117.3]}\end{array}$ & $\begin{array}{c}103.27 \\
{[88.0,120.4]}\end{array}$ & $\begin{array}{c}98.75 \\
{[83.9,115.5]}\end{array}$ & $\begin{array}{c}77.73 \\
{[64.6,92.7]}\end{array}$ & $\begin{array}{c}79.93 \\
{[66.6,95.2]}\end{array}$ & $\begin{array}{c}-1.8 \\
{[-9.2,6.3]}\end{array}$ \\
\hline $20-29$ & $\begin{array}{c}120.02 \\
{[108.1,132.9]}\end{array}$ & $\begin{array}{c}122.79 \\
{[110.9,135.7]}\end{array}$ & $\begin{array}{c}124.81 \\
{[112.0,137.6]}\end{array}$ & $\begin{array}{c}97.79 \\
{[87.4,109.1]}\end{array}$ & $\begin{array}{c}89.14 \\
{[79.3,99.8]}\end{array}$ & $\begin{array}{c}92.35 \\
{[82.5,103.1]}\end{array}$ & $\begin{array}{c}102.31 \\
{[91.9,113.6]}\end{array}$ & $\begin{array}{c}-4.8^{*} \\
{[-9.3,0.0]}\end{array}$ \\
\hline $30-39$ & $\begin{array}{c}56.20 \\
{[48.4,64.9]}\end{array}$ & $\begin{array}{c}49.08 \\
{[41.8,57.2]}\end{array}$ & $\begin{array}{c}49.40 \\
{[42.1,57.6]}\end{array}$ & $\begin{array}{c}49.26 \\
{[41.9,57.4]}\end{array}$ & $\begin{array}{c}37.32 \\
{[31.0,44.5]}\end{array}$ & $\begin{array}{c}46.08 \\
{[39.1,53.9]}\end{array}$ & $\begin{array}{c}49.51 \\
{[42.3,57.6]}\end{array}$ & $\begin{array}{c}-2.7 \\
{[-7.6,2.6]}\end{array}$ \\
\hline $40-49$ & $\begin{array}{c}23.02 \\
{[18.2,28.7}\end{array}$ & $\begin{array}{c}27.52 \\
{[22.3,33.6]}\end{array}$ & $\begin{array}{c}20.60 \\
{[16.1,25.9]}\end{array}$ & $\begin{array}{c}24.27 \\
{[19.4,29.9]}\end{array}$ & $\begin{array}{c}16.35 \\
{[12.5,21.01]}\end{array}$ & $\begin{array}{c}16.85 \\
{[12.9,21.6}\end{array}$ & $\begin{array}{c}18.55 \\
{[14.4,23.6]}\end{array}$ & $\begin{array}{c}-6.5 \\
{[-12.9,0.5]}\end{array}$ \\
\hline Total & $\begin{array}{c}\mathbf{5 8 . 1 6} \\
{[54.1,62.5]}\end{array}$ & $\begin{array}{c}\mathbf{6 2 . 4 5} \\
{[58.2,66.9]}\end{array}$ & $\begin{array}{c}\mathbf{6 0 . 7 5} \\
{[56.6,65.1]} \\
\end{array}$ & $\begin{array}{c}\mathbf{5 5 . 8 2} \\
{[51.9,60,0]}\end{array}$ & $\begin{array}{c}\mathbf{4 8 . 3 5} \\
{[44.6,52.2]}\end{array}$ & $\begin{array}{c}\mathbf{4 8 . 9 2} \\
{[45.3,52.8]}\end{array}$ & $\begin{array}{c}\mathbf{5 3 . 0 8} \\
{[49.3,57.1]}\end{array}$ & 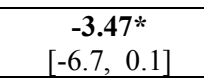 \\
\hline
\end{tabular}

Note: Narrowly-defined AN = F50.0; broadly-defined AN = F50.0 + 50.1; narrowly-defined BN = F50.2; broadly-defined BN = F50.2 $+50.3 ;$ APC $=$ annual percent change; AAPC $=$ average annual percentage change, which is a summary statistic over the entire period. ${ }^{*} \mathrm{p} \leq .05$. 
Figure 1. Average annual percentage change (AAPC) in total (all ages) incidence rates per 100,000 person-years for narrowly and broadly-defined AN and BN (2010-2016)

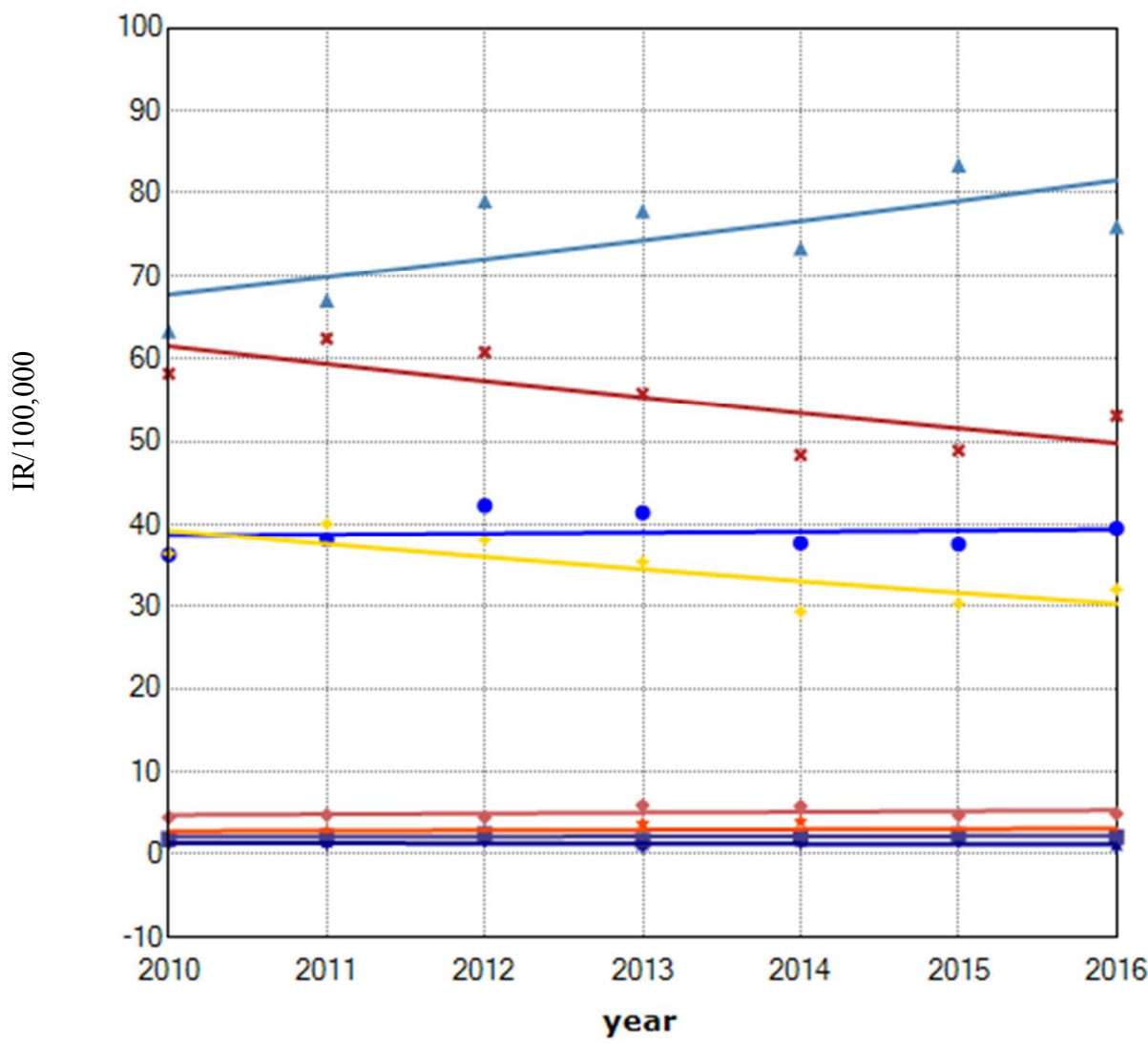

Total Females, Narrow-AN, 2010-2016 AAPC $=0.33$

Total Females, Broad- BN, 2010-2016 AAPC $=-3.47^{*}$

Total Males, Broad- AN, 2010-2016 AAPC $=1.89$

Figure Legend. Multiple joinpoint models depicting observed (plotted as symbols) and modeled (shown as color lines) time-trends in the total incidence rates of narrow and broadly-defined AN and BN both genders. For females (all ages), there was an overall significant decrease in the average annual percent change (AAPC) for narrowlydefined BN (IR 36.36/100,000 to 32.01/100,000 person years) and broadly-defined BN (IR 58.16/100,000 to 53.08/100,000 person years). For males, incidence rates for males were low and no significant trends towards increasing or decreasing IRs were detected. No joinpoints (changes in direction) were observed. * The APPC is statistically significant at an alpha of .05. 
Supplementary Figure S1. Average annual percentage change (AAPC) in age-adjusted incidence rates per 100,000 person-years for broadly-defined AN, females only

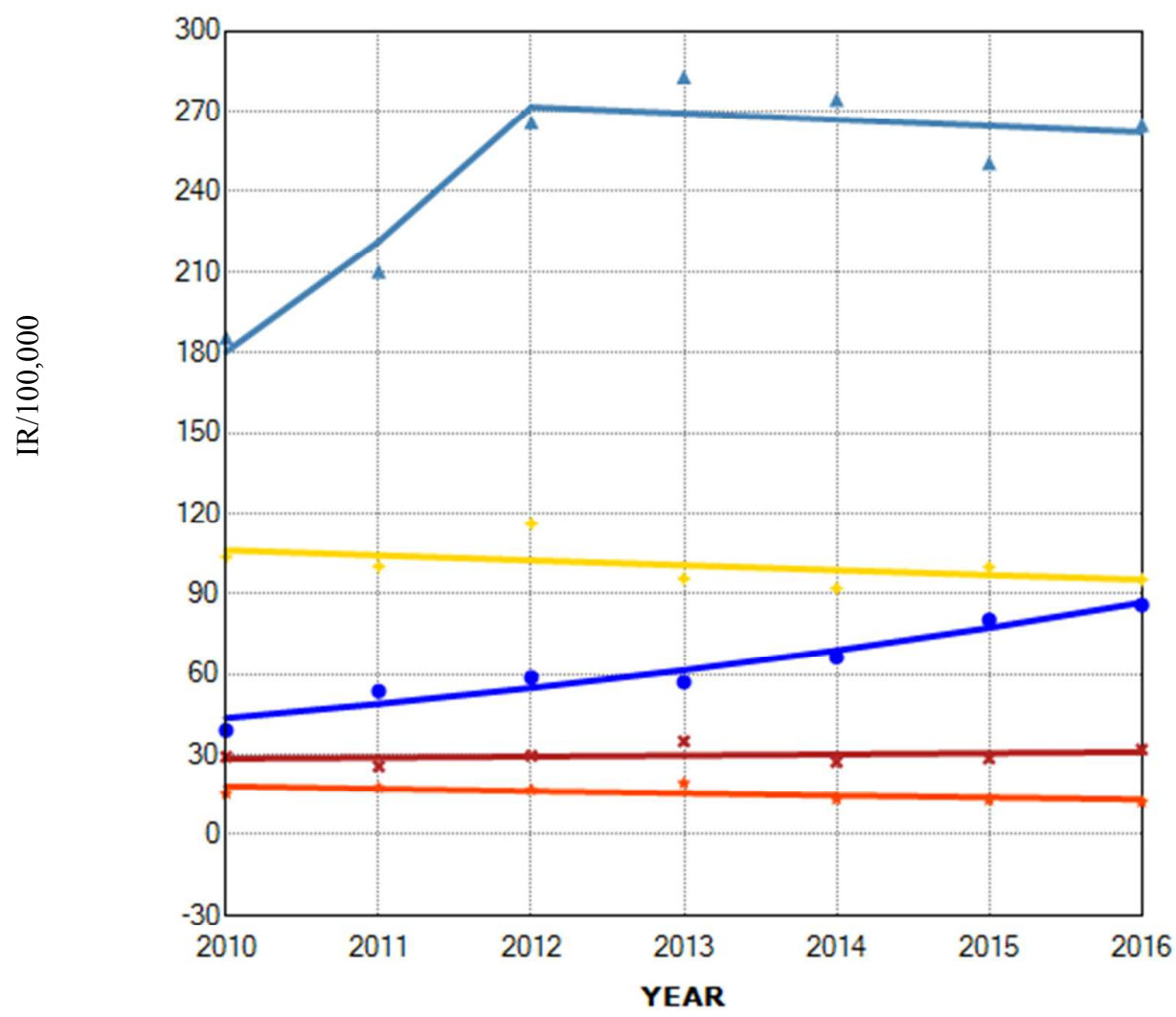

$\bullet$

4

- 15-19 years, 2010-2016 $\mathrm{AAPC}=6.4^{*}$

20-29 years, 2010-2016 AAPC $=-1.79$

* $\quad 30-39$ years, $2010-2016$ AAPC $=1.41$

* 40-49 years, 2010-2016 AAPC $=-5.32$

Figure Legend. Multiple joinpoint models depicting observed (plotted as symbols) and modeled (shown as color lines) time-trends in the female incidence rates of broadlydefined anorexia nervosa (AN). There was a significant increase in the average annual percent change (AAPC) in females aged 10-14 years of $12.1 \%$ per year (IR

$39.13 / 100,000$ to $85.96 / 100,000$ person years). There was also a significant average annual increase in females aged $15-19$ years of $6.4 \%$ per year (IR $185.78 / 100,000$ to

265.02/100,000), with one joinpoint at 2012 [2010-2012 APC $=22.7$ and 2012-2016 APC $=-0.9]$. *The AAPC is statistically significant at an alpha of .05. 
Supplementary Figure S2. Average annual percent change (AAPC) in age-adjusted incidence rates per 100,000 person-years for broadly-defined BN, females only
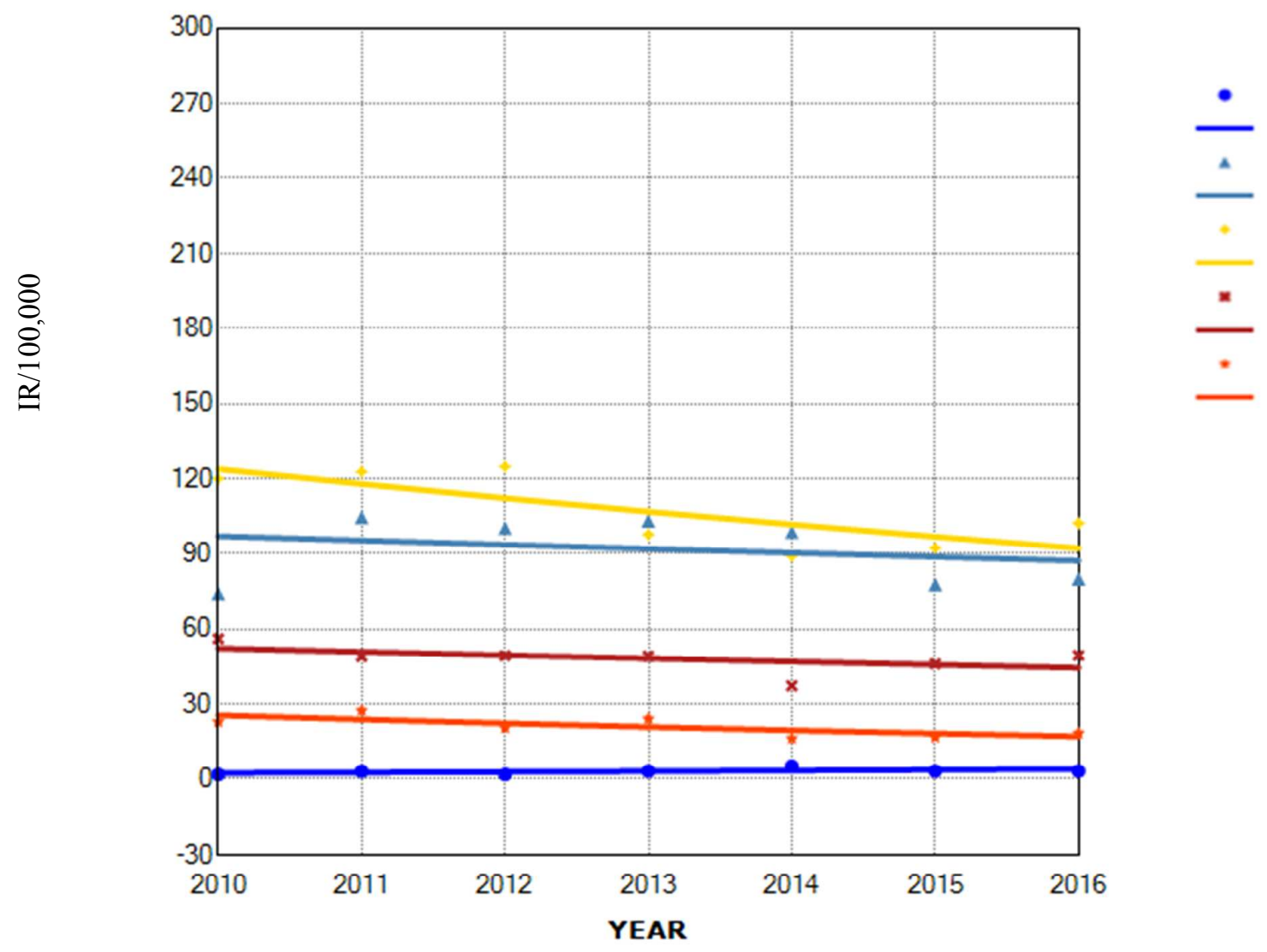

10-14 years, 2009-2016 AAPC $=8.71$ 15-19 years, 2010-2016 AAPC $=-1.77$ 20-29 years, 2010-2016 AAPC $=-4.79 *$ 30-39 years, 2010-2016 AAPC $=-2.66$

- 40-49 years, 2010-2016 AAPC $=-6.48$

Figure Legend. Multiple joinpoint models depicting observed (plotted as symbols) and modeled (shown as color lines) time-trends in the female incidence rates of broadlydefined bulimia nervosa (BN). There was one significant decrease in the average annual percent change for broadly-defined BN for females aged $20-29$ years of $4.79 \%$ per year (IR 120.02 [108.1, 132.9] per 100,000 to 102.31 [91.9, 113.6] per 100,000 person years. AAPC = average annual percent change, which is a summary statistic over the entire time period. * The average annual percentage change is statistically significant at an alpha of .05. 
TRENDS IN INCIDENCE

Supplementary Table S1. Age and year-specific incidence rates $[95 \% \mathrm{CI}]$ per 100,000 and average annual percent change (AAPC), males

\begin{tabular}{|c|c|c|c|c|c|c|c|c|}
\hline Type of ED, age [yrs] & 2010 & 2011 & 2012 & 2013 & 2014 & 2015 & 2016 & $\begin{array}{l}\text { AAPC \% } \\
{[95 \% \text { CI] }}\end{array}$ \\
\hline \multicolumn{9}{|l|}{ Narrowly-defined AN } \\
\hline $10-14$ & $\begin{array}{c}6.18 \\
{[2.96,11.4]}\end{array}$ & $\begin{array}{c}4.36 \\
{[1.75,8.96]}\end{array}$ & $\begin{array}{c}8.19 \\
{[4.36,14.0]}\end{array}$ & $\begin{array}{c}8.25 \\
{[4.39,14.1]}\end{array}$ & $\begin{array}{c}12.08 \\
{[7.28,18.8]}\end{array}$ & $\begin{array}{c}6.37 \\
{[3.06,11.7]}\end{array}$ & $\begin{array}{c}6.33 \\
{[3.04,11.63]}\end{array}$ & $\begin{array}{c}4.64 \\
{[-12.7,25.4]}\end{array}$ \\
\hline $15-19$ & $\begin{array}{c}6.01 \\
{[2.88,11.05]}\end{array}$ & $\begin{array}{c}10.15 \\
{[5.91,16.3]}\end{array}$ & $\begin{array}{c}8.96 \\
{[5.01,14.7]}\end{array}$ & $\begin{array}{c}10.12 \\
{[5.9,16.2]}\end{array}$ & $\begin{array}{c}9.52 \\
{[5.4,15.5]}\end{array}$ & $\begin{array}{c}5.35 \\
2.44,10.2]\end{array}$ & $\begin{array}{c}8.33 \\
{[4.55,13.9]}\end{array}$ & $\begin{array}{c}1.07 \\
{[-13.0,12.5]}\end{array}$ \\
\hline $20-29$ & $\begin{array}{c}1.58 \\
{[0.05,3.69]}\end{array}$ & $\begin{array}{c}2.29 \\
{[1.05,4.82]}\end{array}$ & $\begin{array}{c}1.48 \\
{[0.05,3.45]}\end{array}$ & $\begin{array}{c}4.34 \\
{[2.43,7.15]}\end{array}$ & $\begin{array}{c}3.12 \\
{[1.55,5.57]}\end{array}$ & $\begin{array}{c}3.90 \\
{[2.13,6.54]}\end{array}$ & $\begin{array}{c}1.38 \\
{[0.04,3.21]}\end{array}$ & $\begin{array}{c}7.26 \\
{[-17.5,39.5]}\end{array}$ \\
\hline $30-39$ & $\begin{array}{c}0.87 \\
{[0.02,2.5]}\end{array}$ & $\begin{array}{c}0.87 \\
{[0.02,2.6]}\end{array}$ & $\begin{array}{c}0.00 \\
{[0.00,0.00]}\end{array}$ & $\begin{array}{c}1.42 \\
{[0.05,3.32]}\end{array}$ & $\begin{array}{c}1.98 \\
{[0.08,4.07]}\end{array}$ & $\begin{array}{c}0.84 \\
{[0.02,2.46]}\end{array}$ & $\begin{array}{c}0.83 \\
{[0.02,2.43]}\end{array}$ & $---{ }^{a}$ \\
\hline $40-49$ & $\begin{array}{c}0.83 \\
{[0.02,2.41]}\end{array}$ & $\begin{array}{c}0.82 \\
{[0.02,2.37]}\end{array}$ & $\begin{array}{c}1.33 \\
{[0.04,3.12]}\end{array}$ & $\begin{array}{c}0.79 \\
{[0.02,2.30]}\end{array}$ & $\begin{array}{c}1.04 \\
{[0.03,2.66]}\end{array}$ & $\begin{array}{c}0.78 \\
{[0.02,2.27]}\end{array}$ & $\begin{array}{c}0.78 \\
{[0.02,2.29]}\end{array}$ & $\begin{array}{c}-2.33 \\
{[-13.7,10.5]}\end{array}$ \\
\hline Total & $\begin{array}{c}\mathbf{2 . 2 2} \\
{[1.49,3.16]}\end{array}$ & $\begin{array}{c}\mathbf{2 . 7 0} \\
{[1.83,3.63]}\end{array}$ & $\begin{array}{c}\mathbf{2 . 7 4} \\
{[1.93,3.75]}\end{array}$ & $\begin{array}{c}\mathbf{3 . 7 0} \\
{[2.76,4.86]}\end{array}$ & $\begin{array}{c}\mathbf{3 . 9 5} \\
{[2.98,5.13]}\end{array}$ & $\begin{array}{c}\mathbf{2 . 6 7} \\
{[1.88,3.65]}\end{array}$ & $\begin{array}{c}\mathbf{2 . 2 4} \\
{[1.52,3.15]}\end{array}$ & $\begin{array}{c}\mathbf{1 . 8 3} \\
{[-11.0,16.5]}\end{array}$ \\
\hline \multicolumn{9}{|l|}{ Broadly-defined AN } \\
\hline $10-14$ & $\begin{array}{c}8.03 \\
{[4.28,13.7]}\end{array}$ & $\begin{array}{c}8.09 \\
{[4.31,13.8]}\end{array}$ & $\begin{array}{c}10.8 \\
{[5.76,16.4]}\end{array}$ & $\begin{array}{c}12.69 \\
{[7.75,19.6]}\end{array}$ & $\begin{array}{c}17.17 \\
{[11.3,24.9]}\end{array}$ & $\begin{array}{c}8.28 \\
{[4.41,14.2]}\end{array}$ & $\begin{array}{c}9.49 \\
{[5.13,15.7]}\end{array}$ & $\begin{array}{c}5.10 \\
{[-11.4,24.7]}\end{array}$ \\
\hline $15-19$ & $\begin{array}{c}11.42 \\
{[6.87,17.8]}\end{array}$ & $\begin{array}{c}15.53 \\
{[10.1,22.8]}\end{array}$ & $\begin{array}{c}14.33 \\
{[9.18,21.3]}\end{array}$ & $\begin{array}{c}17.87 \\
{[12.1,25.5]}\end{array}$ & $\begin{array}{c}13.69 \\
{[8.68,20.5]}\end{array}$ & $\begin{array}{c}10.70 \\
{[6.34,16.9]}\end{array}$ & $\begin{array}{c}17.25 \\
{[11.5,24.8]}\end{array}$ & $\begin{array}{c}2.02 \\
{[-7.6,12.6]}\end{array}$ \\
\hline $20-29$ & $\begin{array}{c}4.74 \\
{[2.65,7.82]}\end{array}$ & $\begin{array}{c}4.89 \\
{[2.79,7.95]}\end{array}$ & $\begin{array}{c}3.56 \\
{[1.83,6.21]}\end{array}$ & $\begin{array}{c}5.78 \\
{[3.53,8.93]}\end{array}$ & $\begin{array}{c}5.38 \\
{[3.24,8.40]}\end{array}$ & $\begin{array}{c}7.52 \\
{[4.96,10.9]}\end{array}$ & $\begin{array}{c}5.24 \\
{[3.15,8.18]}\end{array}$ & $\begin{array}{c}6.18 \\
{[-4.0,17.4]}\end{array}$ \\
\hline $30-39$ & $\begin{array}{c}2.60 \\
{[1.19,4.94]}\end{array}$ & $\begin{array}{c}1.44 \\
{[0.05,3.36]}\end{array}$ & $\begin{array}{c}0.86 \\
{[0.02,2.5]}\end{array}$ & $\begin{array}{c}2.28 \\
{[0.09,4.48]}\end{array}$ & $\begin{array}{c}2.26 \\
{[0.09,4.45]}\end{array}$ & $\begin{array}{c}1.40 \\
{[0.05,3.27]}\end{array}$ & $\begin{array}{c}0.83 \\
{[0.17,2.43]}\end{array}$ & $\begin{array}{c}-8.10 \\
{[-25.2,12.8]}\end{array}$ \\
\hline $40-49$ & $\begin{array}{c}1.38 \\
{[0.04,3.21]}\end{array}$ & $\begin{array}{c}1.35 \\
{[0.04,3.16]}\end{array}$ & $\begin{array}{c}2.13 \\
{[0.09,4.19]}\end{array}$ & $\begin{array}{c}1.31 \\
{[0.04,3.06]}\end{array}$ & $\begin{array}{c}1.30 \\
{[0.04,3.03]}\end{array}$ & $\begin{array}{c}1.30 \\
{[0.04,3.03]}\end{array}$ & $\begin{array}{c}1.31 \\
{[0.42,3.05]}\end{array}$ & $\begin{array}{c}-3.28 \\
{[-13.2,7.8]}\end{array}$ \\
\hline Total & $\begin{array}{c}\mathbf{4 . 4 3} \\
{[3.31,5.62]}\end{array}$ & $\begin{array}{c}\mathbf{4 . 7 4} \\
{[3.65,6.04]}\end{array}$ & $\begin{array}{c}\mathbf{4 . 4 6} \\
{[3.35,5.64]}\end{array}$ & $\begin{array}{c}\mathbf{5 . 9 1} \\
{[4.64,7.24]}\end{array}$ & $\begin{array}{c}\mathbf{5 . 7 9} \\
{[4.54,7.10]}\end{array}$ & $\begin{array}{c}\mathbf{4 . 7 0} \\
{[3.64,5.97]}\end{array}$ & $\begin{array}{c}\mathbf{4 . 8 9} \\
{[3.81,6.18]}\end{array}$ & $\begin{array}{c}\mathbf{1 . 8 9} \\
{[-4.4,8.6]}\end{array}$ \\
\hline
\end{tabular}

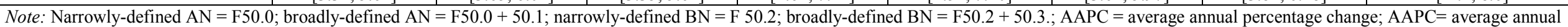
percent change. ${ }^{a}$ At least one annual crude incidence rate $=0$. Joinpoint will not analyze by groups which include records with 0 counts. ${ }^{*} p \leq .05$. 
TRENDS IN INCIDENCE

Supplementary Table S1 (cont). Age and year- specific incidence rates $[95 \% \mathrm{CI}]$ and average annual percent change (AAPC) per 100,000, males

\begin{tabular}{|c|c|c|c|c|c|c|c|c|}
\hline Type of ED, age [yrs] & 2010 & 2011 & 2012 & 2013 & 2014 & 2015 & 2016 & $\begin{array}{l}\text { AAPC \% } \\
{[95 \% \text { CI }]}\end{array}$ \\
\hline \multicolumn{9}{|l|}{ Narrowly-defined BN } \\
\hline $10-14$ & $\begin{array}{c}0.00 \\
{[0.00,0.00]}\end{array}$ & $\begin{array}{c}0.00 \\
{[0.00,0.00]}\end{array}$ & $\begin{array}{c}0.00 \\
{[0.00,0.00]}\end{array}$ & $\begin{array}{c}0.00 \\
{[0.00,0.00]}\end{array}$ & $\begin{array}{c}1.91 \\
{[0.04,5.60]}\end{array}$ & $\begin{array}{c}0.00 \\
{[0.00,0.00]}\end{array}$ & $\begin{array}{c}0.00 \\
{[0.00,0.00]}\end{array}$ & $--{ }^{a}$ \\
\hline $15-19$ & $\begin{array}{c}0.00 \\
{[0.00,0.00]}\end{array}$ & $\begin{array}{c}1.79 \\
{[0.04,5.35]}\end{array}$ & $\begin{array}{c}1.79 \\
{[0.04,5.3]}\end{array}$ & $\begin{array}{c}1.79 \\
{[0.04,5.2]}\end{array}$ & $\begin{array}{c}1.79 \\
{[0.04,5.2]}\end{array}$ & $\begin{array}{c}3.57 \\
{[1.31,7.76]}\end{array}$ & $\begin{array}{c}1.78 \\
{[0.04,5.21]}\end{array}$ & $--^{\mathrm{a}}$ \\
\hline $20-29$ & $\begin{array}{c}3.16 \\
{[1.52,5.82]}\end{array}$ & $\begin{array}{c}1.53 \\
{[0.05,3.56]}\end{array}$ & $\begin{array}{c}0.89 \\
{[0.02,2.6]}\end{array}$ & $\begin{array}{c}2.89 \\
{[1.39,5.32]}\end{array}$ & $\begin{array}{c}2.83 \\
{[1.36,5.21]}\end{array}$ & $\begin{array}{c}1.39 \\
{[0.45,3.25]}\end{array}$ & $\begin{array}{c}1.93 \\
{[0.078,3.97]}\end{array}$ & $\begin{array}{c}-4.41 \\
{[-22.1,17.3]}\end{array}$ \\
\hline $30-39$ & $\begin{array}{c}2.31 \\
{[0.09,4.56]}\end{array}$ & $\begin{array}{c}0.87 \\
{[0.018,2.53]}\end{array}$ & $\begin{array}{c}2.29 \\
{[0.09,4.52]}\end{array}$ & $\begin{array}{c}0.85 \\
{[0.02,2.49]}\end{array}$ & $\begin{array}{c}0.85 \\
{[0.02,2.47]}\end{array}$ & $\begin{array}{c}0.84 \\
{[0.02,2.46]}\end{array}$ & $\begin{array}{c}0.83 \\
{[0.02,2.43]}\end{array}$ & $\begin{array}{c}-16.64 \\
{[-31.8,2.0]}\end{array}$ \\
\hline $40-49$ & $\begin{array}{c}0.83 \\
{[0.02,2.41]}\end{array}$ & $\begin{array}{c}0.81 \\
{[0.02,2.37]}\end{array}$ & $\begin{array}{c}1.60 \\
{[0.06,3.47]}\end{array}$ & $\begin{array}{c}1.31 \\
{[0.04,3.06]}\end{array}$ & $\begin{array}{c}0.78 \\
{[0.02,2.23]}\end{array}$ & $\begin{array}{c}0.78 \\
{[0.02,2.27}\end{array}$ & $\begin{array}{c}0.78 \\
{[0.02,2.29]}\end{array}$ & $\begin{array}{c}-4.70 \\
{[-20.8,14.6]}\end{array}$ \\
\hline Total & $\begin{array}{c}\mathbf{1 . 3 3} \\
{[0.78,2.10]}\end{array}$ & $\begin{array}{c}\mathbf{1 . 2 4} \\
{[0.72,1.98]}\end{array}$ & $\begin{array}{c}\mathbf{1 . 5 8} \\
{[0.93,2.31]}\end{array}$ & $\begin{array}{c}\mathbf{0 . 9 3} \\
{[0.44,1.49]}\end{array}$ & $\begin{array}{c}\mathbf{1 . 4 1} \\
{[0.80,2.09]}\end{array}$ & $\begin{array}{c}\mathbf{1 . 5 4} \\
{[0.90,2.25]}\end{array}$ & $\begin{array}{c}\mathbf{0 . 9 1} \\
{[0.43,1.46]}\end{array}$ & $\begin{array}{c}\mathbf{- 1 . 8 1} \\
{[-12.4,10.1]}\end{array}$ \\
\hline \multicolumn{9}{|l|}{ Broadly-defined BN } \\
\hline $10-14$ & $\begin{array}{c}0.00 \\
{[0.00,0.00]}\end{array}$ & $\begin{array}{c}0.00 \\
{[0.00,0.00]}\end{array}$ & $\begin{array}{c}0.00 \\
{[0.00,0.00]}\end{array}$ & $\begin{array}{c}0.00 \\
{[0.00,0.00]}\end{array}$ & $\begin{array}{c}1.91 \\
{[0.04,5.57]}\end{array}$ & $\begin{array}{c}0.00 \\
{[0.00,0.00]}\end{array}$ & $\begin{array}{c}0.00 \\
{[0.00,0.00]}\end{array}$ & $--^{a}$ \\
\hline $15-19$ & $\begin{array}{c}0.00 \\
{[0.00,0.00]}\end{array}$ & $\begin{array}{c}2.98 \\
{[0.09,6.96]}\end{array}$ & $\begin{array}{c}2.98 \\
{[0.09,6.96]}\end{array}$ & $\begin{array}{c}1.79 \\
{[3.68,5.22]}\end{array}$ & $\begin{array}{c}2.98 \\
{[0.09,6.96]}\end{array}$ & $\begin{array}{c}5.34 \\
{[2.24,10.2]}\end{array}$ & $\begin{array}{c}1.78 \\
{[0.04,5.21]}\end{array}$ & $--^{a}$ \\
\hline $20-29$ & $\begin{array}{c}3.48 \\
{[2.12,6.68]}\end{array}$ & $\begin{array}{c}3.98 \\
{[2.11,6.80]}\end{array}$ & $\begin{array}{c}2.96 \\
{[1.42,5.45]}\end{array}$ & $\begin{array}{c}1.45 \\
{[0.05,3.37]}\end{array}$ & $\begin{array}{c}4.25 \\
{[2.38,7.01]}\end{array}$ & $\begin{array}{c}4.46 \\
{[2.54,7.24]}\end{array}$ & $\begin{array}{c}4.68 \\
{[2.73,7.50]}\end{array}$ & $\begin{array}{c}5.81 \\
{[-7.8,21.5]}\end{array}$ \\
\hline $30-39$ & $\begin{array}{c}2.89 \\
{[1.38,5.32]}\end{array}$ & $\begin{array}{c}2.31 \\
{[0.09,4.54]}\end{array}$ & $\begin{array}{c}3.15 \\
{[1.57,5.64]}\end{array}$ & $\begin{array}{c}3.41 \\
{[1.76,5.96]}\end{array}$ & $\begin{array}{c}1.41 \\
{[0.05,3.3]}\end{array}$ & $\begin{array}{c}1.40 \\
{[0.05,3.3]}\end{array}$ & $\begin{array}{c}1.39 \\
{[0.04,3.25]}\end{array}$ & $\begin{array}{c}-9.55 \\
{[-34.6,25.1]}\end{array}$ \\
\hline $40-49$ & $\begin{array}{c}1.38 \\
{[0.04,3.21]}\end{array}$ & $\begin{array}{c}1.35 \\
{[0.04,3.16]}\end{array}$ & $\begin{array}{c}2.39 \\
{[1.01,4.50]}\end{array}$ & $\begin{array}{c}1.31 \\
{[0.43,3.06]}\end{array}$ & $\begin{array}{c}1.30 \\
{[0.04,3.03]}\end{array}$ & $\begin{array}{c}1.30 \\
{[0.04,3.03]}\end{array}$ & $\begin{array}{c}1.31 \\
{[0.04,3.05]}\end{array}$ & $\begin{array}{c}-4.13 \\
{[-16.8,10.5]}\end{array}$ \\
\hline Total & $\begin{array}{c}\mathbf{1 . 9 2} \\
{[1.19,2.72]}\end{array}$ & $\begin{array}{c}\mathbf{2 . 1 9} \\
{[1.47,3.12]}\end{array}$ & $\begin{array}{c}\mathbf{2 . 4 5} \\
{[1.69,3.42]}\end{array}$ & $\begin{array}{c}\mathbf{1 . 7 1} \\
{[1.09,2.54]}\end{array}$ & $\begin{array}{c}\mathbf{2 . 2 6} \\
{[1.54,3.18]}\end{array}$ & $\begin{array}{c}\mathbf{2 . 3 9} \\
{[1.65,3.33]}\end{array}$ & $\begin{array}{c}\mathbf{2 . 1 0} \\
{[1.35,2.91]}\end{array}$ & $\begin{array}{c}\mathbf{1 . 1 7} \\
{[-5.1,7.8]}\end{array}$ \\
\hline
\end{tabular}

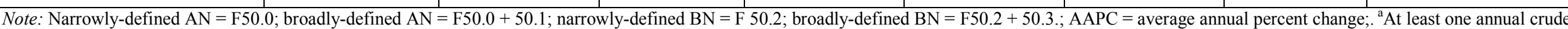
incidence rate $=0$. Joinpoint will not analyze by groups which include records with 0 counts. ${ }^{*} \mathrm{p} \leq .05$. 